
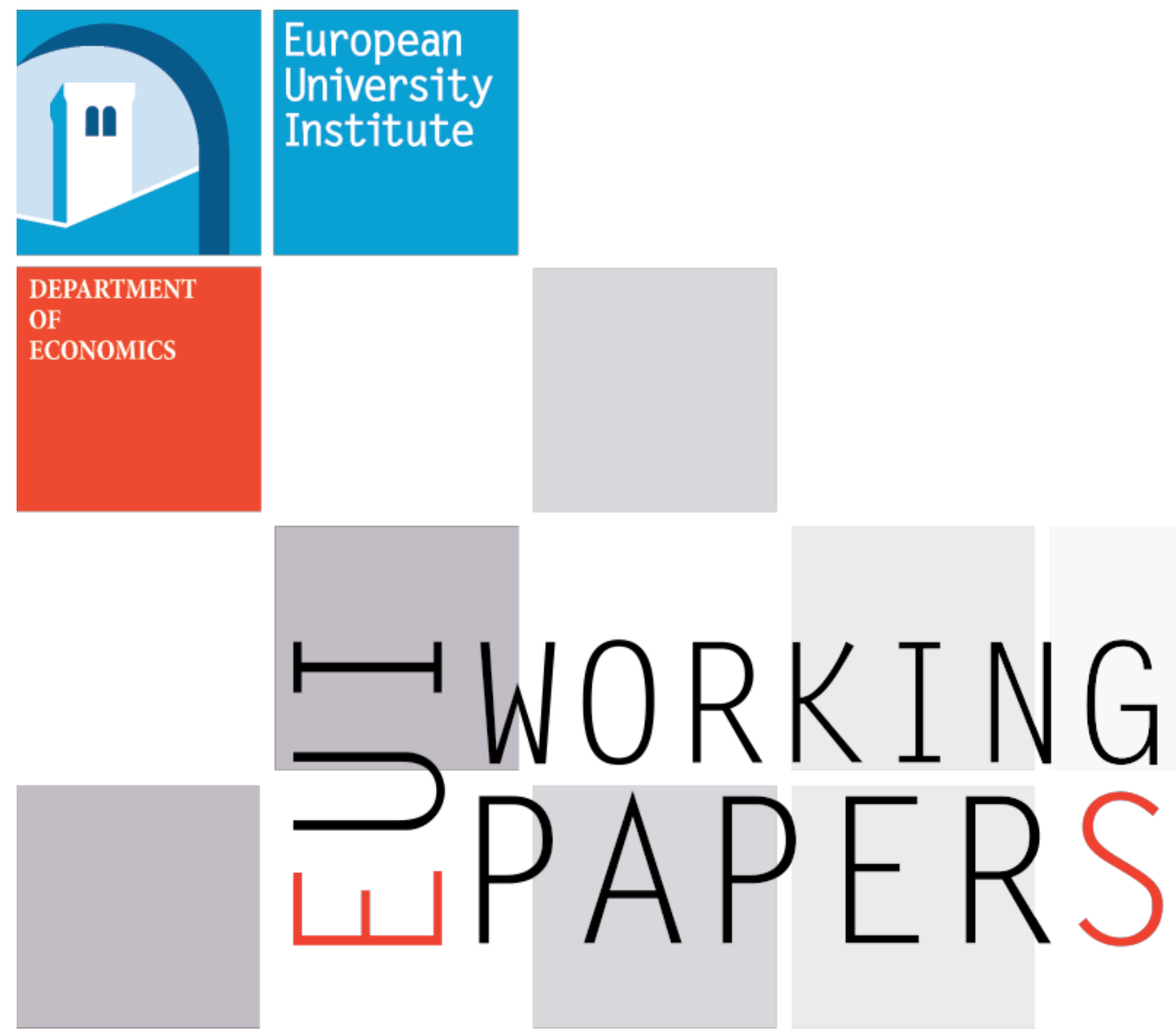

ECO 2016/05

Department of Economics

The Political Economy of Services Trade Agreements

Matteo Fiorini and Mathilde Lebrand 

European University Institute

Department of Economics

The Political Economy of Services Trade Agreements

Matteo Fiorini and Mathilde Lebrand

EUI Working Paper ECO 2016/05 
This text may be downloaded for personal research purposes only. Any additional reproduction for other purposes, whether in hard copy or electronically, requires the consent of the author(s), editor(s). If cited or quoted, reference should be made to the full name of the author(s), editor(s), the title, the working paper or other series, the year, and the publisher.

ISSN 1725-6704

(C) Matteo Fiorini, Mathilde Lebrand, 2016

Printed in Italy

European University Institute

Badia Fiesolana

I - 50014 San Domenico di Fiesole (FI)

Italy

www.eui.eu

cadmus.eui.eu 


\title{
The Political Economy of Services Trade Agreements*
}

\author{
Matteo Fiorini ${ }^{\dagger} \quad$ Mathilde Lebrand ${ }^{\ddagger}$
}

March 30, 2016

\begin{abstract}
This paper studies the determinants of liberalization commitments in the context of trade in services used as intermediate inputs. Compared to goods, services inputs are mostly complementary to other factors of production and non-tradable. We build a theoretical trade policy framework in which (i) foreign investment as a way to contest a market for non-tradable services can be restricted by the government and (ii) the role of services as complementary inputs explains unilateral commitment to services trade liberalization. Commitment helps governments to avoid political pressures that would result in protectionist measures leading downstream producers to inefficiently reduce their production. In addition we provide new results on the influence of lobbying by both national firms and foreign multinationals. We discuss how the bargaining power of the government, the size of national services sectors and the difference in valuation between national and foreign contributions affect the willingness of the government to sign a services trade agreement.
\end{abstract}

Keywords: services trade; trade agreements; FDI; lobby

JEL Classification: D43, F13, F21, L80

\section{Introduction}

Tariff barriers have almost completely disappeared for manufactured goods but significant restrictions remain for international services transactions. Restrictive policies are observed for professional and transportation services in both industrial and developing countries, and for most sectors in some of the fastest growing countries in Asia and the oil-rich Gulf states (Borchert et al., 2012). ${ }^{1}$ Due to the intangibility and non-storability of many services, their international provision requires the establishment of a commercial presence in the importing country. As a

\footnotetext{
${ }^{*}$ We wish to thank Bernard Hoekman, Paola Conconi, Andrea Mattozzi, Fernando Vega-Redondo and Piero Gottardi for their constant guidance and support. We also thank participants at the ETSG 2014 in Munich, the XII ELSNIT Conference in Florence and the $7^{\text {th }}$ FIW Research Conference in Vienna, as well as seminar participants at EUI and University of Montreal for their useful comments.

${ }^{\dagger}$ Robert Schuman Centre for Advanced Studies (EUI). E-mail: matteo.fiorini@eui.eu

${ }^{\ddagger}$ European University Institute. E-mail: mathilde.lebrand@eui.eu

${ }^{1}$ According to the information provided by the World Bank Services Trade Restrictiveness database (the richest source of services trade policy outcomes in terms of country coverage) the highest barriers to services trade are observed in the high-income GCC countries, South and East Asia, the Middle East and North Africa. Latin America, Eastern Europe and OECD countries are relatively more open while Sub-Saharan Africa shows an intermediate level of services trade openness.
} 
consequence, restrictions on foreign acquisitions, discrimination in licensing and other investment restrictions represent de facto barriers to trade in services. Liberalization in service sectors has become a key element of the international trade agenda and services trade agreements have been proposed to promote integration in the services markets. The Trade in Services Agreement (TiSA) is a recent initiative to push for multilateral negotiations. Services are also the main topic of the 'Market Access' chapter that is negotiated in the Transatlantic Trade and Investment Partnership (TTIP) between the United-States and the European Union. A key stylized fact here is that international agreements have done very little to establish a higher access to service markets. In practice, unilateral policy reforms remain the prime channel through which the major (though incomplete) steps toward liberalization have been made so far. ${ }^{2}$ Why the current framework of services trade agreements is not conducive to the desired policy outcomes is a question that deserves careful consideration and, above all, calls for a deeper understanding of the motives behind commitment to services trade liberalization through an international agreement. While there is little in the way of theoretical investigation on the rationales/motives behind services trade agreements, scholars of services trade policy have advanced several important hypothesis.

First, it has been argued that the non-tradability and non-storability of services weakens the terms-of-trade motive for most services sectors (Hoekman, 2008 and Francois and Hoekman, 2010). Protectionist measures that affect world prices benefit both foreign affiliates and national firms which all produce in the same country and sell at the same price. Blanchard (2010) weakens the importance of this motive but her reasoning is less relevant for services. International ownership for services mostly aims at accessing a market when cross border exports are not possible or not optimal. ${ }^{3}$ Second, the commitment motive model developed by Maggi and Rodriguez-Clare (1998) rests on assumptions and mechanisms that do not fit the specificities of services. Protectionism in services sectors does not primarily reduce the gains from a comparative advantage mechanism (as it happens in that paper), but mostly reduces the benefits from more competition in sectors where monopolies, large entry costs or state-owned firms are predominant. Moreover, these authors only consider final goods whereas services are major inputs for downstream producers (Francois, 1990a). The lack of a theory that fits the specificities of services better, calls for further work. The present paper constitutes a first attempt in rationalizing the motives behind services trade agreements accounting for the characteristics of services production and trade.

We build a new model whose assumptions fit the specificities of services better. First, services are important inputs that are often complementary to other factors; second, trade in services often requires commercial presence; third, services sectors are characterized by significant market imperfections. Our framework features an open economy in which a perfectly competitive downstream sector produces a final consumption good using service and non-service intermediates as complementary inputs. Service inputs can be imported by allowing foreign multinationals to establish a commercial presence (engage in FDI) and operate domestically. National services providers and foreign affiliates operate under a regime of oligopolistic competition. The gov-

\footnotetext{
${ }^{2}$ This key stylized fact is discussed in details in Francois and Hoekman (2010).

3 The terms-of-trade motive is weakened by the rise of international ownership. Governments have less incentives to set high tariffs given that some domestic firms make profits from importing goods and suffer from high tariffs.
} 
ernment chooses the number of foreign providers allowed to contest the services market, with free entry representing the welfare-maximizing policy option. Firms can form lobbies and give contributions in order to have an impact on the government's choice.

We show the existence of a commitment motive for services agreements. The government uses trade policies as a substitute for domestic policies in order to attract foreign multinationals. Imperfect competition in the services sector leads national providers to exert political pressures and lobby for protection against foreign entry. However higher services prices due to protectionist policies leads to underinvestment in the complementary non-services inputs and a lower production of the consumption good. Similarly to Maggi and Rodriguez-Clare (1998), we reveal a time inconsistency problem for the government given that the the 'long run' losses due to the protection of the services sector - which triggers an inefficient scale of the final good industry - are not compensated by the political rents. As a consequence, the government can end up worse off when subject to political pressures than under free entry. In this case there is scope for commitment via an international agreement as a tool for the government to credibly distance itself from the special interest groups and to prevent their lobbying activity.

The literature on services trade policies (Hoekman, 2008 and Francois and Hoekman, 2010) supports the existence of such a commitment motive in which agreements act as a commitment device to avoid domestic political pressures even in the absence of reciprocity channels. One of our contributions is to show that the complementarity between services and non-services inputs in downstream production is key to support the existence of a commitment motive for services.

An additional contribution of our paper is to consider the political influence of foreign firms on the choice of trade policies. We allow foreign providers to coalesce into a lobby and to offer contributions directly to the government. However we assume that governments tend to value a unit of foreign contributions less than the same unit of domestic contributions (Gawande et al., 2006). Two interesting results emerge. First we show that the foreign lobby's optimal policy is not free-entry. The foreign lobby supports lower barriers, i.e. more entry, till the gains from an additional entry are less than the losses due to lower individual profits for all affiliates. We show that whether the foreign lobby pushes for higher or lower market access depends on the number of national services providers. We find that the foreign lobby supports more entry when the number of national firms is large. The economic intuition is simple. The contribution base of the national lobby is large and high barriers tend to be chosen. The gains from an additional foreign firm are higher than the sum of the loses for all foreign firms. In that case foreign lobbying is welfare improving as it counteracts the effect of national lobbying. Second we find that the government's valuation of contributions from foreign firms compared to those from national firms shapes the commitment choice of the government in a non trivial way. In our new framework, we study how the bargaining power of the government, its valuation of foreign contributions and the number of national services providers all interact to explain commitment.

The paper relates to the literature in several respects. First, we provide the existing debate on the motives behind services trade agreements (Hoekman, 2008 and Francois and Hoekman, 2010) with a formal analysis of the commitment rationale for the specific case of trade in services through commercial presence. In doing so, we add to the theoretical work on liberalization in 
producer services (see for instance Francois, 1990b, Francois, 1990a and Markusen et al., 2005). From these models, we keep the assumptions on the role of services as intermediate inputs and the relevance of investment barriers for services trade. We add a political economy dimension to analyse the trade policy outcomes and the role of agreements in case of political pressures. ${ }^{4}$ Our contribution is to develop a model that relies on these assumptions. Some papers have focused on the effect of the rise of trade in intermediate inputs for commercial policy and the design of trade agreement for goods (Antràs and Staiger (2012), Blanchard (2015)). In our paper we go further by focusing on the complementarity between services and other inputs and studying how this affects the willingness of the government to commit to an agreement.

We also contribute to the theoretical literature on the motives behind international agreements. We draw from the seminal work on the commitment motive (Maggi and Rodriguez-Clare, 1998) making it compelling for the case of trade in services. We do this by departing from a comparative advantage model of trade in final goods, by introducing imperfect competition and, most importantly, by focusing on entry barriers instead of tariffs as the relevant policy instruments. Finally, the present paper speaks to existing analysis of foreign lobbying as a determinant of trade policy outcomes (see for instance Gawande et al., 2006). Compared to the existing studies, we consider that the foreign lobby acts as a third agent in the bargaining game. His objective differs from the objectives of both the government and the lobby of national firms. In line with Antràs and Padró i Miquel (2011), we study how foreign lobbying affects the willingness of governments to commit.

Finally, our framework has implications for the empirical study of commitment to services trade liberalization through international agreements (Egger and Lanz, 2008). It suggests that the degree of services input intensity, the complementarity between intermediate services and other factors of production as well as the impact of foreign lobbying and the size of the national services sector should be considered as determinants of participation into services trade and investment agreements.

The rest of the paper is organized as follows. Section 2 discusses some key empirical facts that capture the specificities of services production and trade. Section 3 presents our baseline theoretical model and Section 4 extends it to allow for foreign lobbying. Section 5 offers conclusions.

\section{Stylized facts}

In this part we detail the specificities of services on which rely our modelling assumptions to study the role of services trade agreements.

First services are special inputs into modern production processes, from a quantitative as well as a qualitative perspective. Producer services (accounting, consulting, and computer design services) are important suppliers to the rest of the whole economy. ${ }^{5}$ Good financial and transportation

\footnotetext{
${ }^{4}$ A similar political economy framework can be found in Fung and Siu (2008). These authors however look at the role of political economy forces only for the contingent trade policy outcome while our focus is on the decision to commit via an international agreement.

${ }^{5}$ Averaging across the 63 countries covered by the OECD Inter Country Input Output (ICIO) database, for
} 
services are necessary to expand the production and trade of final goods. Overall, services help to coordinate and control specialized operations involving the other factors of production (Francois, 1990a and Markusen et al., 2005). This is modelled in Francois (1990a) as a complementarity relationship between producer services and other inputs in the production function of the final good. ${ }^{6}$ As a consequence, improving the access and the quality of producer services is a crucial step for the rest of the economy to expand. This is supported by the empirical studies that analyze the effect of reforms in the services sector on downstream manufacturing industries (Arnold et al., 2011, Fernandes and Paunov, 2011). The main result of those studies is that higher services productivity, better access to producer services and pro-competitive reforms targeting the service industry have a positive impact on the economic performance of sectors downstream the supply chain, notably manufacturing. The entry of multinationals in the services sectors is key to get a positive effect. $^{7}$

Trade in services mainly happens through horizontal FDIs, as opposed to cross-border trade. They are typically intangible and non-storable (Jensen (2011)), such that production and consumption must occur at the same place and time. In order to cover all the possible ways to exchange services, the GATS negotiators have defined four mode of services provision: Mode 1 for cross-border trade; Mode 2 when customers move in the exporter's country; Mode 3 for commercial presence (also called horizontal FDI); finally Mode 4 when the exporter's personnel move to the customer's country. In this paper we only focus on horizontal FDIs or Mode 3. This is relevant because a large share of trade in service, especially trade in producer services, happens through horizontal FDI (mode 3). Figures 1 compares cross-border trade (mode 1) with trade through commercial presence (mode 3 ) for US exports and imports respectively. ${ }^{8}$ At the beginning of the nineties the two modes accounted for equal shares of international transactions. Currently, the value of transactions through commercial presence is almost twice the value of transactions through cross-border exchange. Commercial presence is now the main mode of services provision from and to other countries. This can not only be explained by a decrease in barriers to FDIs, a large part of services that have increasingly been traded are intangible and can only be provided through FDIs. In addition an important finding from the empirical literature is that the presence of foreign firms is the key channel for successful liberalization reforms (Arnold

each dollar of national production in 2011, 4.7 cents cover the costs of R\&D and business services as intermediate inputs, 3.7 cents the cost of transportation services, 3.2 cents that of financial services. Additionally, there is often an increasing trend in the evolution of services input intensity from 1995 to 2011: this is the case especially for ICT services, whose cost as intermediate inputs relative to one dollar of total output goes from 0.43 cents in 1995 to 0.86 cents in 2011.OECD ICIO tables cover OECD countries, the BRICS and several other high and middle income countries. For a detailed country coverage of the OECD ICIO tables see http: //www.oecd.org/sti/ind/ICI02015_Countries_Regions.pdf.

${ }^{6}$ More precisely, given that the only factor of production in Francois (1990a) is labor, the complementarity is defined between the labor directly employed for specialised production operations and the labor employed in producer services.

${ }^{7}$ These empirical works include a number of country case studies with firm-level data (such as Arnold et al., 2011, Fernandes and Paunov, 2011, Duggan et al., 2013 and Arnold et al., forthcoming 2015) as well as few crosscountry analysis, often with data at the sector-level (see for instance Arnold et al., 2008, Barone and Cingano, 2011, Bourlès et al., 2013, Hoekman and Shepherd, forthcoming 2015 and Beverelli et al., 2015).

${ }^{8}$ Data on trade in services through commercial presence is not captured in the Balance of Payment Statistics. A good measure of mode 3 services trade is given by the Foreign Affiliates in Trade in Services (FATS) data. Mode 3 exports of a national economy are measured as the sales (abroad) of foreign affiliates of national firms. Specularly, mode 3 imports by a reference country are given by the the sales of those services providers that, while located in the country, are foreign affiliates of non national firms. 
et al. (2011), Fernandes and Paunov, 2011). ${ }^{9}$ There are two explanatory channels: foreign firms bring know-how and knowledge about new products, and foreign firms increase competition in sectors where monopolies and high entry costs are predominant. We focus on the last explanation which is particularly relevant in services sectors.

Figure 1: Modes of provision in US Services exports (left) and imports (right). Source: US BEA
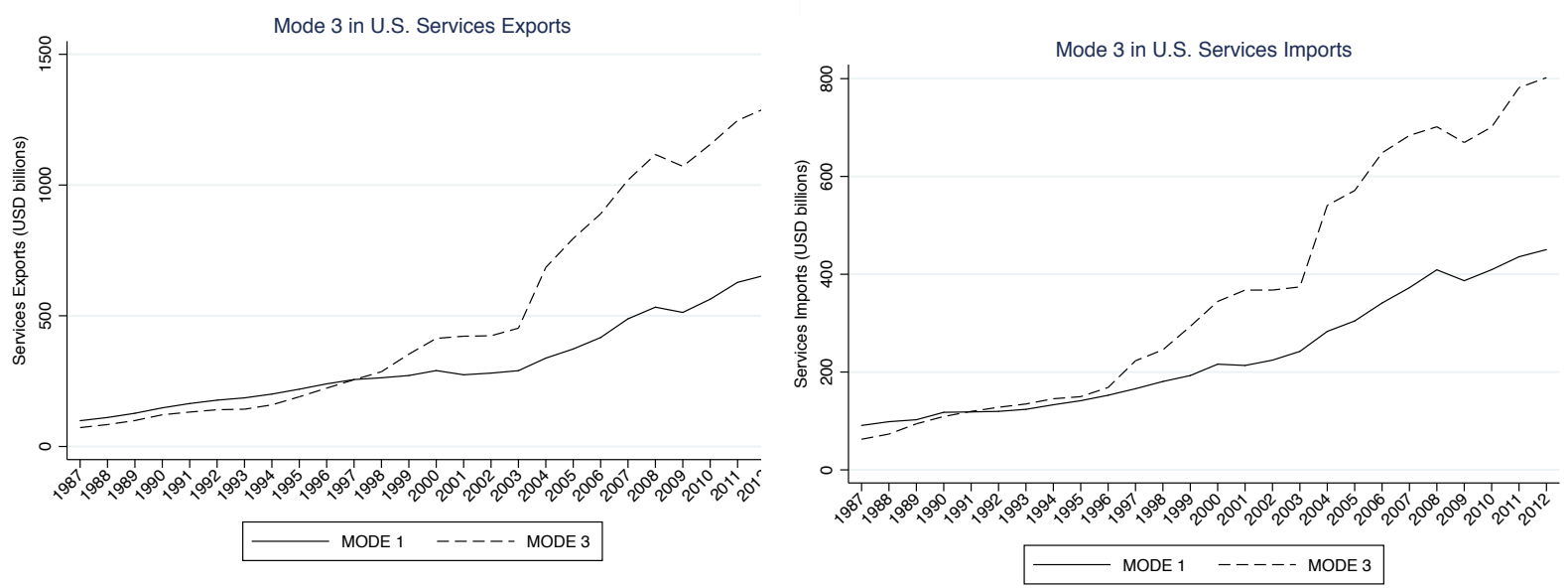

Indeed services sectors are often characterized by a strong degree of market concentration. In their analysis of competition across US industries, Epifani and Gancia (2011) show that services sectors have mark-ups which are from two to three times bigger than the average mark-up in the manufacturing industry. In the same paper the authors argue that the degree of market imperfection is linked to the tradability of an industry's output, highlighting the linkages between market structure and trade policy. Analogously, domestic market imperfections have been identified as main determinants for trade policies (Hoekman, 2008 and Francois and Hoekman, 2010). In many cases, more liberal trade policies act as substitutes for domestic reforms to make services sectors more competitive and improve the provision of intermediate services.

The three facts presented in this section have important implications for the political economy of services trade policy. First, protectionist measures that restrict foreign entry in services sectors directly affect downstream producers. Therefore lobbying from services firms to protect their interests affect the behaviours of all producers using intermediate services and create inefficiencies in the provision of consumption goods. We study here how the government reacts to political pressures and chooses trade policies by weighting the interests of consumers and of all producers. Second, horizontal FDI is the main mode of services provision which means that the relevant trade policies here are barriers that restrict the entry of multinationals. Examples of such policy instruments are foreign equity quotas, limit on the number of licences available, nationality

\footnotetext{
${ }^{9}$ Arnold et al. (2011) highlight that foreign entry in services sectors is the key channel to improve performance in the manufacturing sectors. Foreign firms bring know-how and knowledge about new products. Their presence may also lead domestic providers to improve the quality of their products. The positive role of foreign entrants was also shown by Javorcik et al. (2008). They focus on the Mexican detergent industry and find that the entry of Walmart reduced the distribution cost for detergent manufacturers. Finally Fernandes and Paunov (2011) studies the impact of FDI inflows in producer service sectors on the productivity of Chilean manufacturing firms.
} 
requirements for key personnel and discriminatory licensing criteria. ${ }^{10}$ Moreover, the market power of services firms suggests that national providers are willing to buy protection for their oligopolistic profits against the entry of foreign providers. Given that the role of foreign firms is crucial in improving domestic services sectors, foreign firms should also be considered as important players in the political game between the government and services firms. Foreign firms will also lobby in order to affect the choice of the domestic government. In the next section we develop a theoretical framework that accounts for the role of services as complementary inputs, the role of FDI in trade in services and the market power of services providers. Our positive analysis of services trade policy embeds the political economy forces described above.

\section{Theoretical Model}

\subsection{The set up}

We consider one Home country $(H)$, and the rest of the world. The economic structure in $H$ consists of 2 sectors: a downstream sector $(D)$ and an intermediary services sector $(S)$. We assume a representative consumer receiving utility from the final good domestically-produced by the downstream sector and from a numeraire that represents the rest of production. ${ }^{11}$ Formally, utility is given by:

$$
\mathbb{U}\left(x_{0}, x^{D}\right)=x_{0}+u\left(x^{D}\right) \quad \text { st. } x_{0}+P^{D} x^{D} \leq R
$$

with $x_{0}$ and $x^{D}$ being the consumption respectively of the numeraire and the final good, and $R$ the consumer's income. The demand is a function of price and is assumed to be strictly decreasing and twice continuously differentiable. The function $u$ is quasi-linear and defined by $u(x)=v x-\frac{x^{2}}{2}$. This implies that the demand for the final good only depends on its price, not on the consumer's income.

The downstream sector (or final-good sector) consists of a unit measure continuum of small firms, operating under perfect competition. The firms produce a final good using services and other inputs. We model all non-services inputs as an input bundle denoted by $k$ and owned by consumers. Consistently with the coordination role of services inputs, we assume a complementarity relationship between services and $k$. Downstream producers operate through the following production function:

$$
F\left(k, d^{S}\right)=f\left(\min \left\{k, d^{S}\right\}\right)
$$

with the usual assumptions on $f$ being increasing and strictly concave. $k$ and $d^{S}$ are the demands for the input bundle and services from each individual downstream producer. ${ }^{12}$ We focus here on a partial equilibrium model neglecting the impact of services trade policy for non-services upstream markets. The supply of $k$ is assumed unlimited and its price is fixed and denoted by

\footnotetext{
${ }^{10}$ For a comprehensive discussion on the relationship between modes of provision and policy instruments see Francois and Hoekman (2010).

${ }^{11}$ The numeraire is produced with constant returns to scale with a cost per unit of one which implies that its price is equal to one.

${ }^{12}$ Notice that our assumption on the competitive structure of sector $D$ implies that final-goods producers take inputs and output prices as given. By doing so we prevent any strategic behaviour among downstream firms.
} 
$\tau$. The profit of a downstream producer is given by

$$
\pi^{D}\left(k, d^{S}\right)=P^{D} F\left(k, d^{S}\right)-P^{S} d^{S}-\tau k
$$

with $P^{D}$ the price of the final good and $P^{S}$ the price of services inputs. All downstream firms are identical so that the aggregate profit function is given by $\Pi^{D}=\int_{0}^{1} \pi^{D} \mathrm{~d} j=\pi^{D}$. Similarly, the aggregate demand for the input bundle is $K=k$ and the aggregate demand of services inputs is $D^{S}=d^{S}$.

The services sector is characterised by a finite number $n$ of firms that operate under a regime of oligopolistic competition à la Cournot. We assume that services are non tradable through cross-border exports. Foreign services can only be provided through commercial presence (FDI / Mode 3). ${ }^{13}$ In order to access the $H$ market, foreign firms have to establish a commercial presence (open an affiliate) in the country and employ domestic $(H)$ specific factors. We assume no cost for opening an affiliate. The revenues from specific factor ownership is given by the profits of the services sector. ${ }^{14}$ Once foreign firms are allowed to contest the $H$ market, there is no difference between a Home firm and a Foreign firm any more. Services can therefore be provided by either Home national firms or by affiliates of foreign services providers. We denote by $n_{d}$ the number of national providers and we take it as an exogenous parameter. ${ }^{15}$ The remaining $n-n_{d}$ services firms operating within the domestic market are affiliates of a foreign firm.

Notice that the owners of the specific factor used by the affiliates of foreign providers own claims on the services sector's profits in the same way as those agents whose specific factor is used by the national services firms. All the $n$ services providers are identical in terms of production capacity and they all take the price of the final good $P^{D}$ as given. The profits of a services firm are given by:

$$
\pi^{S}\left(q^{S}\right)=q^{S} P^{S}\left(Q_{-}^{S}+q^{S}\right)
$$

with $P^{S}(\cdot)$ the price of services given by the strategic behavior of the firms in a Cournot framework. This price depends on the aggregate supply of services, which is equal to the individual supply of the firm $q^{S}$ plus the aggregate supply of all the others, $Q_{-}^{S}$.

We now turn to the political structure of the economy. We assume a national government in country $H$ that can choose the level of market access in the services sector. More precisely, the government takes as given the number of national firms $n_{d}$ and sets a value for $n$ which directly determines the number of foreign suppliers allowed to operate in the country.

Firms in the services sector are able to coalesce into lobbies that can offer contributions to the government. The rationale behind the lobbying activity comes from oligopolistic competition in the services sector. Indeed, services providers make positive profits depending on the their total number $n$. Importantly, two lobbies can be formed: the 'national lobby' that represents national

\footnotetext{
${ }^{13}$ We do not model trade in downstream production.

${ }^{14}$ We assume that the production of services requires only the use of a sector-specific factor that is available in inelastic supply and non-tradable. The sector-specific model has been used in the literature as exemplified by Grossman and Helpman (1994) or Buzard (2014).

${ }^{15}$ This implies that our model has a short-term perspective that does not consider the impact of new national firms.
} 
services providers and the 'foreign lobby' that aggregates the interests of foreign firms. Denoting with $c$ and $c^{f}$ the contributions of the national and the foreign lobby respectively, their objective function are given by:

$$
L(n, c)=n_{d} \pi^{S}(n)-c
$$

and

$$
L^{f}(n, c)=\left(n-n_{d}\right) \pi^{S}(n)-c^{f}
$$

In case of inactive lobbies the government maximises the welfare given by the sum of the consumer's surplus, the services and downstream producers' surplus and the rents from the input bundle. ${ }^{16}$ Given that the $n-n_{d}$ foreign affiliates use domestic specific factors, the rents from the national firms and the foreign affiliates are equally considered in the revenue of the representative consumer. The social welfare maximised by the government is given by:

$$
W(n)=H(n)+\Pi^{D}(n)+\Pi^{S}(n)+\tau K
$$

where $H(n)$ is the consumer surplus that only depends on the price $P^{D}(n),{ }^{17}$ and

$$
\Pi^{S}(n)=\underbrace{n_{d} \pi^{S}(n)}_{\text {national firms }}+\underbrace{\left(n-n_{d}\right) \pi^{S}(n)}_{\text {foreign affiliates }}
$$

When instead special interest groups are active, each lobby pays a contribution to the government in order to have an influence on the trade policy $n$. The government's objective is the weighted sum of the social welfare and contributions:

$$
G(n, c)=a W(n)+c+\gamma c^{f}
$$

where $a$ is the weight on the social welfare. The parameter $\gamma$ varies between 0 and 1 and measures to which extent foreign contributions are valued with respect to national ones. Following Gawande et al. (2006), we assume imperfect foreign lobbying: the government will never value one dollar of foreign contributions strictly more than one dollar of national ones. ${ }^{18}$ When $\gamma=0$, foreign lobbying is considered as forbidden or totally inefficient. When instead $\gamma=1$, foreign contributions are perfectly valued by the government, i.e. there is no difference in valuation between national and foreign contributions.

The timing of the economy is the following. At $t=0$ there are $n_{d}$ domestic firms and no foreign services providers. At the first stage, $t=1$, the downstream producers buy the non-services input bundle $K$. No production takes place. In the second stage, $t=2$, the government chooses its trade policy by fixing $n$, the total number of services firms allowed to operate in the market. We call this the trade policy stage. Notice that this timing reflects the idea that both the government and

\footnotetext{
${ }^{16}$ This results is given by the definition of the welfare in a partial equilibrium with a quasi-linear utility function and a numeraire that represents the rest of the economy.

17 The consumer surplus is $H\left(P^{D}\right)=\frac{\left(v-P^{D}\right)^{2}}{2}$.

18 The rationale behind $\gamma \leq 1$ is linked to the risks run by policymakers when accepting contributions from foreign entities, this being potentially considered as non consistent with national interests and therefore punished by the voters.
} 
the lobbies lack commitment with respect to the downstream producers. Relevant downstream economic decisions, exemplified by the purchase of the input bundle $K$, have to be taken as given in the political game. Finally, at $t=3$, production in the services sector takes place. The price of services $P^{S}$ is determined and the downstream firms buy services inputs. Production and consumption of the final goods take place.

We are now ready to solve for the equilibrium of the model. We start deriving a benchmark solution from the simplest case of national lobbying only. Section 4 extends the discussion to foreign lobbying.

\subsection{The equilibrium with national lobbying}

We proceed by backward induction. We start describing the incentives of the producers and consumers in the final stage $(t=3)$, given the level of $K$ and the trade policy decided in the previous periods. Then we move to the trade policy stage where, for a given $K$, a political game between the government and the active lobby determines the number of foreign firms to enter the domestic services sector. Finally, we solve for the optimal aggregate level of the input bundle purchased by downstream producers at $t=1$. In this section we assume no foreign lobbying $(\gamma=0)$.

\subsubsection{The final stage $(t=3)$}

Optimal demand for services inputs. At $t=3$, downstream producers have already bought the input bundle $k$ and its cost $\tau$ is therefore sunk. ${ }^{19}$ With $k$ given, the demand for services of an individual downstream producer solves the following maximisation problem

$$
\max _{d^{S}} P^{D} f\left(d^{S}\right)-P^{S} d^{S}-\tau k \quad \text { subject to } \quad d^{S} \leq k
$$

and it is implicitly defined as a function of the two prices $d^{S}\left(P^{S}, P^{D}\right)$. Finally, all firms are similar so the aggregate demand of services is $D^{S}\left(P^{S}, P^{D}\right)$ with $D^{S}(\cdot)=\int_{0}^{1} d^{S}(\cdot) d i=d^{S}(\cdot) . D^{S}$ can be written as

$$
D^{S}\left(P^{S}, P^{D}\right)= \begin{cases}\left(f^{\prime}\right)^{-1}\left(\frac{P^{S}}{P^{D}}\right) & \text { if }\left(f^{\prime}\right)^{-1}\left(\frac{P^{S}}{P^{D}}\right) \leq K \\ K & \text { otherwise }\end{cases}
$$

Optimal behaviour of the services firms. The problem of a services firm is as follows:

$$
\max _{q^{S}} q^{S} P^{S}\left(Q_{-}^{S}+q^{S}\right)
$$

\footnotetext{
${ }^{19}$ If the two decisions on $k$ and services inputs had taken place simultaneously, the maximisation problem of a representative downstream firm would have been given by

$$
\max _{\left\{k, d^{S}\right\}} P^{D} f\left(\min \left\{k, d^{S}\right\}\right)-P^{S} d^{S}-\tau k
$$

with solution $d^{S}=k$ and $k$ determined from $P^{D} f^{\prime}(k)=P^{S}+\tau$.
} 
with $P^{S}\left(Q_{-}^{S}+q^{S}\right)=P^{D} f^{\prime}\left(Q_{-}^{S}+q^{S}\right)$ given the oligopolistic framework. We use the aggregate demand in services goods (3.11) considering a non binding constraint. ${ }^{20}$ In addition, we impose the functional form $f(x)=1-e^{-\frac{x}{A}}$ with $A$ positive constant. ${ }^{21}$ The aggregate services supply is given by:

$$
Q^{S}\left(P^{D}\right)=n A
$$

Optimal behaviour of the representative consumer The consumer only consumes the final good. The demand function is

$$
D^{D}\left(P^{D}\right)=v-P^{D}
$$

Market clearing First, the aggregate supply $Q^{S}$ of services has to match the demand from all downstream producers

$$
Q^{S}\left(P^{D}\right)=D^{S}\left(P^{S}, P^{D}\right)
$$

Second, the aggregate production of the final good has to equalize the demand $D^{D}(\cdot)$ of the representative consumer

$$
f\left(K, D^{S}\left(P^{S}, P^{D}\right)\right)=D^{D}\left(P^{D}\right)
$$

The equilibrium of production. Given the level of $K$ and the trade policy $n$, the equilibrium in the production stage is defined by the final good price $P^{D}(K, n)$ and the services price $P^{S}(K, n)$ that satisfy the optimal behaviour of the representative consumer, the optimal behaviour of the services and downstream firms and the market clearing conditions for the final goods and the service intermediate input.

Downstream firms use services and the complementary input bundle and choose their production plan according to the prices of the two inputs $\left(P^{S}, \tau\right)$. For simplicity, we assume for the rest of the paper that the price of $k$ is low enough so that the complementarity of inputs implies that only the relative price of the services affects the final firms' decision. Therefore the initial aggregate purchase of the input bundle is not binding - $K \geq D^{S}$ - and the demand function for the service input is simply given by $D^{S}\left(P^{S}, P^{D}\right)=\left(f^{\prime}\right)^{-1}\left(\frac{P^{S}}{P^{D}}\right)$. This imply the following price equations

$$
\begin{gathered}
P^{D}(K, n)=v-f(n A) \\
P^{S}(K, n)=[v-f(n A)] f^{\prime}(n A)
\end{gathered}
$$

Finally, standard comparative statics analysis shows that an increase in the total number of services firms $n$ (i) decreases the price of services inputs $P^{S}$, (ii) decreases the final price $P^{D}$, and (iii) decreases the profit made by each services firm. ${ }^{22}$

\footnotetext{
${ }^{20}$ The focus on the case where $\left(f^{\prime}\right)^{-1}\left(\frac{P^{S}}{P^{D}}\right) \leq K$ will be rationalised below when setting the value for $\tau$.

21 This functional form is chosen for tractability reasons. It results in a constant optimal individual supply function $q^{S}\left(P^{D}\right)=A$.

${ }^{22}$ In order to keep these comparative statics results straightforward we assume $v>f(\cdot)$. This allows the derivative of $\pi^{S}$ with respect to $n$ to be negative for any positive value of $A$. For analogous technical reasons, pertaining to subsequent derivations, we further assume $v$ to be smaller than 1.
} 


\subsubsection{The trade policy stage $(t=2)$}

Trade policy $n$ and contributions $c$ are determined through a cooperative bargaining game between the government and the lobby (Maggi and Rodriguez-Clare, 1998). The threat point is given by the trade policy $n_{0}$, chosen by the government in case of no political distortions, and zero contributions. $n_{0}$ coincides with free entry for foreign services providers. ${ }^{23}$ Following Binmore et al. (1986), we assume that the two players are different in terms of procedural abilities and preferences (time preferences or attitudes towards risk), which implies heterogeneity in bargaining power. We denote the bargaining weights $\sigma$ and $1-\sigma$, for the government and the lobby respectively. The solution $\left(n^{N}, c^{N}\right)$ maximises the Nash product: ${ }^{24}$

$$
\left(n^{N}, c^{N}\right)=\underset{(c, n) \in \mathbb{R} \times \mathbb{R}^{+}}{\operatorname{argmax}}\left[a W(n \mid K)+c-a W\left(n_{0} \mid K\right)\right]^{\sigma} \times\left[n_{d} \pi^{S}(n \mid K)-c-n_{d} \pi^{S}\left(n_{0} \mid K\right)\right]^{1-\sigma}
$$

Notice that the solution of the political game $\left(n^{N}, c^{N}\right)$ with the national lobby is efficient, i.e. it maximizes the joint surplus of the government and of the national lobby given by

$$
\mathbb{J}^{N}(n)=a W(n \mid K)+n_{d} \pi^{S}(n \mid K)
$$

A detailed derivation of this result is given in Appendix A.

Finally, it is important to highlight that the threat point gives the government a utility $W\left(n_{0} \mid K\right)$ which differs from the one in a game with no active lobbies. If the political distortions associated with special interest groups are removed, downstream producers do not expect any form of protectionism to increase the price of services inputs. On the contrary, in the political game with lobbying, the aggregate purchase of the input bundle $(K)$ is made given the expectations of political frictions over the trade policy decision.

\subsubsection{The initial stage $(t=1)$}

Downstream firms are assumed to be small and, as a consequence, unable to individually affect the aggregate demand for the input bundle. Given the complementarity between services and $k$, the optimal demand for services determined in the final stage $(t=3)$ represents an upper threshold for $k$ 's demand. We can write the initial stage maximisation program of downstream producers using the expected services demand from the final stage $d^{S}=\left(f^{\prime}\right)^{-1}\left(\frac{P^{S}}{P^{D}}\right)$.

$$
\max _{k} P^{D} f(k)-P^{S} d^{S}-\tau k \quad \text { subject to } \quad k \leq\left(f^{\prime}\right)^{-1}\left(\frac{P^{S}}{P^{D}}\right)
$$

When the constraint is not binding the solution is given by the first order condition $P^{D} f^{\prime}(k)=\tau$, otherwise $k$ is equal to the optimal unconstrained services demand. This defines the aggregate

\footnotetext{
${ }^{23}$ Technically this is given by setting the individual profits of services firms equal to $0: \pi^{S}(n)=0$.

${ }^{24}$ The superscript $N$ denotes the solution of the political game when only the national lobby is active.
} 
demand for $k$ :

$$
K\left(P^{S}, P^{D}\right)=\min \left\{\left(f^{\prime}\right)^{-1}\left(\frac{\tau}{P^{D}}\right),\left(f^{\prime}\right)^{-1}\left(\frac{P^{S}}{P^{D}}\right)\right\}
$$

The assumption on $\tau$ (low enough to guarantee that $K \geq\left(f^{\prime}\right)^{-1}\left(\frac{P^{S}}{P^{D}}\right)$ in the final stage) reduces the aggregate demand for $k$ to

$$
K\left(P^{S}, P^{D}\right)=\left(f^{\prime}\right)^{-1}\left(\frac{P^{S}}{P^{D}}\right)
$$

Given our assumption of an unlimited supply of $k$, aggregate demand is always met. Importantly, our simple framework implies that the aggregate demand for $k$ is decreasing in the relative price of services. Therefore, if services become more expensive, the downstream producers will demand less of the other inputs.

\subsubsection{Equilibrium}

We can now define the equilibrium of the model when the government plays a political game with the national lobby.

Definition 1 (Equilibrium under national lobbying) The equilibrium of the model with inactive foreign lobbying is defined by the vector

$$
E^{N}:=\left\{n^{N}, c^{N}, K^{N},\left(P^{S}\right)^{N},\left(P^{D}\right)^{N}\right\}
$$

that satisfies the optimal behaviour of the representative consumer in (3.14); the optimal demand of services and $k$ from downstream firms given by equations (3.11) and (3.23); the optimal supply from services firms in (3.13); the optimal trade policy (3.19); and all market clearing conditions, (3.15) and (3.16).

The equilibrium reflects coming from the economic as well as political structure of our setting. The government wants a high entry of foreign firms in order to decrease the price of services. On the contrary, the number of national firms is fixed and their aggregate profits therefore only depends on the individual profit of each firm. Individual profits in the services sector are decreasing in the trade policy parameter $n$ which defines the number of domestic (national and foreign) services suppliers. Therefore, the rent owners value protection of the services sector against foreign entrants. Their first-best trade policy would be a closed domestic services sector $\left(n=n_{d}\right)$. In order to influence the trade policy choice, the national lobby offers contributions to the government through a bargaining process. The equilibrium trade policy results in a number of domestically active foreign providers that is non zero (closed economy) but lower than the free-entry level (fully open economy).

Technically, the equilibrium trade policy $n^{N}$ and contributions $c^{N}$ are derived from the first order conditions of the Nash product - equation (3.19) - after having expressed all other relevant quantities as a function of $n$. In particular, the complementarity assumption between services and $k$ and the market clearing condition for services imply that $K=D^{S}=Q^{S}=n A$. 
The key properties of the equilibrium are given in the following

Proposition 1 The equilibrium $E^{N}$ exists and is unique. The equilibrium trade policy $n^{N}$ is given by

$$
n^{N}=-\ln \left(\frac{(1-v)\left(a-n_{d}\right)}{a-2 n_{d}}\right)
$$

which is increasing in the government's social valuation (a) and decreasing in the number of national services providers $\left(n_{d}\right)$.

Proof. See Appendix A.

The equilibrium number of services firms $n^{N}$ increases in the government's valuation of social welfare (the $a$ parameter). Intuitively, given that setting no entry restrictions is the welfare maximising trade policy, if the government puts less weight on political rents (contributions), it will reduce the barriers to foreign entry by choosing a higher value of $n$. Instead, the total number of services providers decreases in the exogenous number of national services firms, $n_{d}$. A larger national services sector makes it more rewarding for the government to decrease the number of foreign entries.

\subsection{The political game versus unilateral commitment}

Similarly to Maggi and Rodriguez-Clare (1998), we allow the government to commit to its optimal trade policy at $t=0$, i.e. before any economic decision is taken by the downstream producers. We assume that government commitment at $t=0$ is perfectly enforceable. As a consequence, if the government commits at the beginning, the subsequent trade policy stage does not take place and there is no political game between the government and the lobby. The welfare maximising trade policy $n_{0}$ is associated with no entry restrictions for foreign services firms. It is given by the following zero-profit condition in the services sector

$$
\pi^{S}\left(n_{0}\right)=0 \Longleftrightarrow v-f\left(n_{0} A\right)=0 \Longleftrightarrow n_{0}=-\ln (1-v)
$$

Notice that positive contributions in the equilibrium with the political game assure that $n^{N}<n_{0}$ : indeed, the national lobby is willing to offer contributions with the precise objective to increase protection beyond the welfare maximising policy $n_{0} \cdot{ }^{25}$

Importantly, the aggregate demand for the input bundle under commitment is given by $K_{0}=n_{0} A$. This quantity is strictly bigger than $K^{N}$, the aggregate demand for $k$ in the equilibrium without commitment. Downstream producers anticipate the distorted equilibrium trade policy when the government chooses not to commit. This implies a higher services price than under commitment. Given the complementarity of services input and $k$, a higher price for services leads to a smaller

\footnotetext{
${ }^{25}$ See the proof of Proposition 1 for the technical restrictions on the parameters implied by a well defined equilibrium with national lobbying.
} 
demand for the input bundle. Formally

$$
K_{0}-K^{N}=A \ln \left(\frac{a-n_{d}}{a-2 n_{d}}\right)>0
$$

The difference in the equilibrium aggregate input bundle is decreasing in governments valuation of social welfare and increasing in the number of national services firms $n_{d}$. Formally

$$
\frac{\partial\left(K_{0}-K^{N}\right)}{\partial a} \leq 0 \quad \text { and } \quad \frac{\partial\left(K_{0}-K^{N}\right)}{\partial n_{d}} \geq 0
$$

The intuition behind this result is simple. First, a government that cares more about social welfare (higher value of $a$ ) is less influenced by contributions from services firms. The policy chosen in the political game is then closer to its optimal when there is no lobbying. Therefore, downstream producers expect the price of services to be closer to the free-entry benchmark. This will allow them to buy more services at $t=3$. Anticipating this higher demand for services and given the complementarity of services and $k$, downstream producers buy more input bundle at $t=1$. Secondly, a higher number of national firms (higher $n_{d}$ ) implies that the national lobby is stronger and that the government cares more about the individual profits of the national firms. This leads the government to choose higher restrictions (lower value of $n$ ), which in turns imply a higher services price. Downstream producers will then buy less services at $t=3$. The services- $k$ complementarity in production and the anticipation of a lower demand for services in the final stage, lead the final good firms to buy less of $k$ at $t=1$.

We can now describe the optimal decision of the government at $t=0$, whether to commit to $n_{0}$ or to do nothing, waiting to play the political game with the lobby during the subsequent trade policy stage. Similar to Maggi and Rodriguez-Clare (1998), the timing is important and creates a time-inconsistency problem that explains why the government might not always opt for the political game. Indeed, when playing the political game at $t=2$, the government is constrained by the choice of the downstream producers from $t=1$. The optimal allocation gives the government his outside option plus a share of the surplus. However the outside option is not the first-best any more. Indeed, the lower aggregate purchase of $k$ by downstream firms prevents the government to get $W\left(n_{0}\right)$. The government gets its constrained first-best $W\left(n_{0} \mid K\right)$ plus a share of the surplus that depends on its bargaining power and therefore it be worse off with respect to the benchmark case where it obtains $W\left(n_{0}\right)$. Under commitment instead, the government has the opportunity to set its trade policy at $t=0$ before any relevant economic decision by the downstream producers. The enforcement is perfect such that the policy chosen cannot be renegotiated. In other words, the government can commit to free-entry $\left(n_{0}\right)$ and tie his hands vis-à-vis the special interest group. The trade-off between the rents from the lobby (cost of commitment) and the lower input bundle purchase by the downstream firms (cost of the political game) pins down the value of commitment, defined as the difference between the objective of the government under commitment - $G_{0}$ - and the one under the political game, $G^{N}$ :

$$
\Omega=G_{0}-G^{N}=a W\left(n_{0}, K_{0}\right)-a W\left(n^{N}, K^{N}\right)-c^{N}
$$


The following proposition details the choice of the government at $t=0$.

Proposition 2 (i) If $\sigma=0$, the government always benefits from commitment: $\Omega(\sigma=0)>0$. (ii) There exists a unique threshold $V \in(0,1)$ such that $\forall v<V, \exists$ ! $\bar{\sigma} \in(0,1)$ such that $\Omega(\bar{\sigma})=0$. Moreover, when the government has a weak bargaining power $(\sigma<\bar{\sigma})$ it benefits from commitment $(\Omega(\sigma)>0)$; when instead the government has a strong bargaining power $(\sigma>\bar{\sigma})$ it benefits from the political game $(\Omega(\sigma)<0)$.

Proof. See Appendix A.

Proposition 2 shows that, when the government has a low bargaining power, the rents it can extract from the lobby above its reservation utility are small. ${ }^{26}$ Therefore the cost of commitment (foregone contributions) is smaller than the cost of playing the political game (lower purchase of $k$ ) and the government optimally chooses to initially commit to a unilateral trade policy. On the contrary, a strong government can extract big political rents (above its reservation utility) and therefore chooses not to commit at $t=0$. Under technical restriction on the parameter $v$, there always exists a level of bargaining power above which the cost of commitment is larger than the cost of playing the political game.

Crucial for the decision to commit is the assumption of complementarity between services and other intermediate inputs represented by $k$. While the time inconsistency setting is not new to the literature on the commitment motive, the inefficiency coming from input complementarity is, to the best of our knowledge, an original contribution of our framework. To further clarify the relevance of our complementarity assumption, let us take the opposite stance and assume perfect substitutability between services and $k$ in downstream production. In that case the government never commits at $t=0$.

Under perfect substitutability, downstream firms buy either only $k$ if $\tau \leq P^{S}$ or only services if $\tau \geq P^{S}$. If $k$ is cheaper, there is no production in the services sectors. Interestingly, when services are expected to be cheaper, downstream firms optimally choose not to buy any other intermediate input. When the government chooses its trade policy at a later stage, no purchase of $k$ has been made and the government can get as an outside option its unconstrained first-best $W\left(n_{0}, K_{0}\right)$. In any case, the government never wants to commit as he always gets compensated by the lobbies in the bargaining game. This shows that unilateral commitment as an outcome depends on the complementarity assumption between services and non-services inputs. ${ }^{27}$

We have described the commitment motive that explains why governments might want to unilaterally commit to a trade agreement when services are inputs for downstream productions and

${ }^{26}$ The threshold $\bar{\sigma}$ has the following analytical expression

$$
\bar{\sigma}=\frac{a\left[W\left(n_{0} \mid K_{0}\right)-W\left(n_{0} \mid K^{N}\right)\right]}{\Pi\left(n^{N} \mid K^{N}\right)-\Pi\left(n_{0} \mid K^{N}\right)}
$$

that comes from the loss of the government by not choosing its first-best when playing the bargaining game (numerator) and from the gains of the lobby that are to be shared (denominator).

${ }^{27}$ While here we only discuss the two extreme cases of perfect complementarity and perfect substitutability, further work can be done on the link between the elasticity of substitution between inputs and commitment to liberalization in the services sectors. The analysis in this paper suggests that more liberal commitments should be observed in sectors that are characterized by a lower elasticity of substitution with other types of inputs. 
are provided by foreign affiliates in the host country. Such commitment motive arises when lobbying by national firms leads to entry restrictions. Downstream producers underbuy non-services inputs anticipating a higher price for services inputs. This creates a time-inconsistency problem that might lead the government to choose to initially commit.

\section{The role of foreign lobbying}

So far we have assumed that only national firms can coalesce into a lobby. In this section we relax this assumption and study the outcome of a game where foreign multinationals can form a lobby and offer contributions to the domestic government (foreign lobbying). Foreign firms' interests differ from national firms' interests. Several issues arise here. Do foreign firms always lobby for more entry? What is the outcome when both national and foreign firms can lobby? What happens when governments undervalue foreign contributions?

The objective function of the lobby of foreign multinationals ("foreign lobby") differs from the one of the lobby of national firms ("national lobby"). It is given by $L^{f}\left(n, c^{f}\right)=\left(n-n_{d}\right) \pi^{f}(n)-c^{f}$ with $c^{f}$ the contribution that is given to the government. Whereas the national lobby' objective is maximized in no foreign entry $\left(n=n_{d}\right)$, the optimal policy of the foreign lobby is neither no entry $\left(n=n_{d}\right)$ nor free-entry $\left(n=n_{0}\right)$, and is given by:

$$
\tilde{n}=\underset{n}{\operatorname{argmax}}\left(n-n_{d}\right) \pi^{f}(n) \quad \text { with } \quad n_{d} \leq \tilde{n} \leq n_{0} \quad \wedge \quad \pi^{f}(\tilde{n})=-\left(\tilde{n}-n_{d}\right) \pi^{f^{\prime}}(\tilde{n})
$$

The lobby of foreign firms maximizes the sum of all affiliates' profits and pushes for more entry till the gain from an additional entry $\left(\pi^{f}(n)\right)$ is lower than the aggregate loses from all decreasing profits $\left(-\left(n-n_{d}\right) \pi^{f^{\prime}}(n)\right)$. Free-entry increases the number of foreign firms that benefit from entering the domestic market but individual profits are decreasing in the number of total producers $\left(\pi^{f^{\prime}}(n)<0\right)$. We therefore distinguish the extensive margins of the foreign lobby's interest line - which consists in the number of foreign affiliates allowed to enter - and the intensive margins, i.e. the individual profits made by each foreign affiliate. Given that the lobby maximizes the aggregate profit of those foreign affiliates, there is a trade-off between increasing the extensive margins (a less restrictive policy) and increasing the intensive margins (a more restrictive policy).

In this part we assume that both the national and the foreign lobby can offer contributions to the Home government. A similar framework with national and foreign interest groups has been applied in other papers. For example, Gawande et al. (2006) study the role of foreign lobbying and assume that foreign contributions are imperfectly valued by the government. Compared to this work, we model the game between the government and the two lobbies as a bargaining game. The government does not value a unit of foreign contributions as a unit of national contributions. To capture this imperfection, we add to the government's objective the parameter $\gamma$ with $0 \leq \gamma \leq 1$. When $\gamma=0$, foreign lobbying is considered as forbidden or totally inefficient. When instead $\gamma=1$, foreign contributions are perfectly valued by the government, i.e. there is no difference in valuation between national and foreign contributions. Formally, the government's 
objective function is:

$$
G\left(n, c, c^{f}\right)=a W(n)+\mathbb{I} c+\gamma c^{f}
$$

The dummy $\mathbb{I}$ is used to study the case where only foreign lobbying takes place $(\mathbb{I}=0)$.

The bargaining game solutions are given by the maximization of the Nash product

$$
\left(n^{\gamma}, c^{\gamma}, c^{f, \gamma}\right)=\operatorname{argmax}\left[G(\cdot)-G_{0}\right]^{\sigma_{G}}\left[L^{N}(\cdot)-L_{0}^{N}\right]^{\sigma_{N}}\left[L^{F}(\cdot)-L_{0}^{F}\right]^{\sigma_{F}}
$$

The threat point is given here by full liberalization $\left(n=n_{0}\right)$, and no political contributions $\left(c=c^{f}=0\right)$. At this stage - when the government chooses its trade policy - the level of investment by the downstream firms is already chosen and its cost sunk. Therefore the threat point is constrained by the optimal decision of the downstream firms that, anticipating future political frictions, underinvested at the beginning: $G_{0}=a W\left(n_{0} \mid K\right), L_{0}^{N}=\Pi\left(n_{0} \mid K\right)$ and $L_{0}^{N}=\Pi^{D}\left(n_{0} \mid K\right)$. The FOCs of the Nash product maximization imply that the new trade policy $n^{\gamma}$ maximizes $a W(n)+n_{d} \pi(n)+\gamma\left(n-n_{d}\right) \pi(n)$ where the aggregate profits of the foreign affiliates are less valued than the profits of the national firms.

Definition 2 The equilibrium of the model with foreign lobbying is defined by the vector

$$
E^{\gamma}:=\left\{n^{\gamma}, c^{\gamma}, c^{f, \gamma}, K^{\gamma},\left(P^{S}\right)^{\gamma},\left(P^{D}\right)^{\gamma}\right\}
$$

that satisfies the optimal behaviour of the representative consumer in (3.14); the optimal demand of services and non-services inputs $k$ from downstream firms given by equations (3.11) and (3.23); the optimal supply from services firms in (3.13); the optimal trade policy, national and foreign contributions (4.3); and all market clearing conditions, (3.15) and (3.16).

For simplicity the policy when only foreign firms lobby $n^{\gamma}(\mathbb{I}=0)$ is denoted by $n^{F}$.

Proposition 3 The equilibrium exists and is unique. The equilibrium policy is given by:

$$
n^{\gamma}=-\ln \left(\frac{(1-v)\left(a+\gamma-\gamma n^{\gamma}-(\mathbb{I}-\gamma) n_{d}\right)}{\left(a+\gamma-2 \gamma n^{\gamma}-2(\mathbb{I}-\gamma) n_{d}\right)}\right)
$$

We can show that

1. if only foreign lobbying takes place $(\mathbb{I}=0$ and $\gamma=1)$, there exists a threshold in the number of domestic firms ( $n_{d}^{=}$) such that

$$
\left\{\begin{array}{lll}
n_{d} \leq n_{d}^{=} & \Rightarrow & n^{\gamma}(\mathbb{I}=0)=n^{F} \leq n^{N} \\
n_{d} \geq n_{d}^{\bar{y}} & \Rightarrow & n^{\gamma}(\mathbb{I}=0)=n^{F} \geq n^{N}
\end{array}\right.
$$

Compared to national lobbying, foreign lobbying only is welfare improving when the number of domestic firms is large enough $\left(n_{d} \geq n_{d}^{=}\right)$.

2. if both national and foreign lobbying take place $(\mathbb{I}=1$ and $0 \leq \gamma \leq 1)$, there exists a threshold 
in the number of domestic firms $\left(\widehat{n}_{d}\right)$ such that

$$
\left\{\begin{array}{l}
n_{d} \leq \widehat{n}_{d} \quad \Rightarrow \quad \frac{\partial n^{\gamma}}{\partial \gamma} \leq 0 \wedge n^{\gamma} \leq n^{N} \\
n_{d} \geq \widehat{n}_{d} \quad \Rightarrow \quad \frac{\partial n^{\gamma}}{\partial \gamma} \geq 0 \wedge n^{\gamma} \geq n^{N}
\end{array}\right.
$$

A higher valuation of foreign contributions by the government leads to a higher level of entry, i.e. lower restrictions, only when the number of domestic firms is large enough $\left(n_{d} \geq \widehat{n}_{d}\right)$. Compared to national lobbying only, Foreign lobbying is here welfare improving only when the number of domestic firms is small enough $\left(n_{d} \leq \widehat{n}_{d}\right)$

Proof. See Appendix A.

Proposition 3 offers results for two cases: foreign lobbying only (1.) and both national and foreign lobbying (2.). It is interesting to detail the case of foreign lobbying only in order to understand the role of foreign firms when both national firms and affiliates can lobby. Figure ?? offers a qualitative illustration of the result. When the number of national firms is large

Figure 2: The case of one lobby: the national lobby versus the foreign lobby.

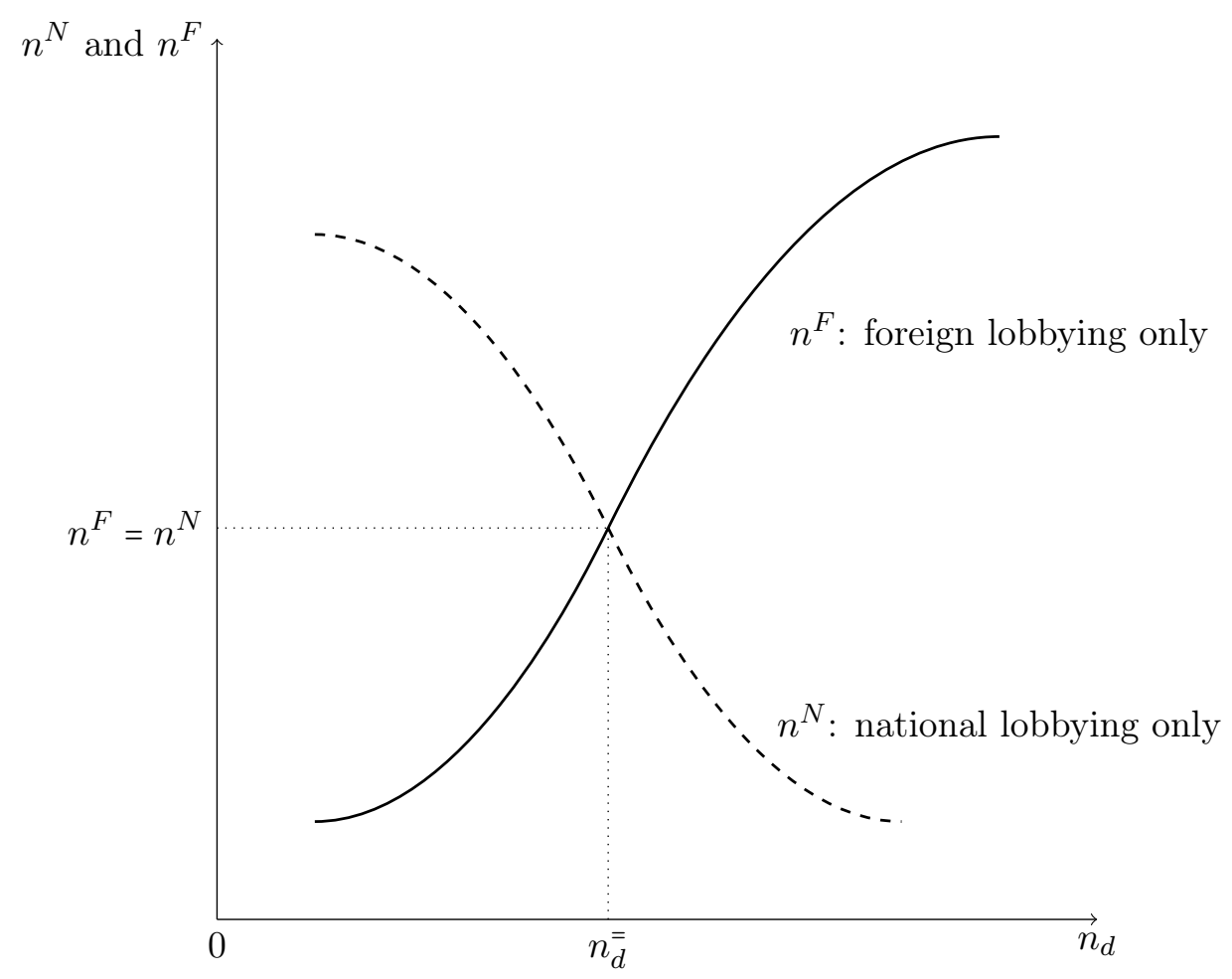

enough $\left(n_{d} \geq n_{d}^{=}\right)$, the result is intuitive. The policy is higher when only foreign affiliates can lobby rather than only national firms. A high number of national firms implies that they have a relatively high influence on the government. The policy is therefore a low number of foreign affiliates. From the perspective of foreign firms, there are already a lot of national producers in the market so it is more likely that the gain from one additional entry remains larger than the loses from the decreasing profits. ${ }^{28}$ The lobby of foreign firms therefore pushes for more entry.

\footnotetext{
${ }^{28}$ This is due to the concavity of individual profits with respect to the number of producers. The marginal lose
} 
In that case foreign lobbying is welfare improving because it leads to a higher number of total producers in the services market. When the number of national firms is small $\left(n_{d} \leq n_{d}^{=}\right)$, the result is counter-intuitive. The policy chosen when only foreign firms lobby is lower than the one when only national firms lobby. A low number of national firms means that the national lobby is rather weak and the policy that is chosen in case of national lobbying is not restrictive. On the opposite, a low number of national firms implies a potentially high number of foreign affiliates. The latter are numerous enough to push for more restrictions in order to protect their individual profits. The intensive margin exceeds the extensive margin. In that case foreign lobbying is not welfare improving because it leads to a lower number of total producers in the services market. This illustrates the complex role of the lobby of foreign firms.

Figure 3: Trade policy $n^{\gamma}$ under imperfect foreign lobbying $0 \leq \gamma \leq 1$

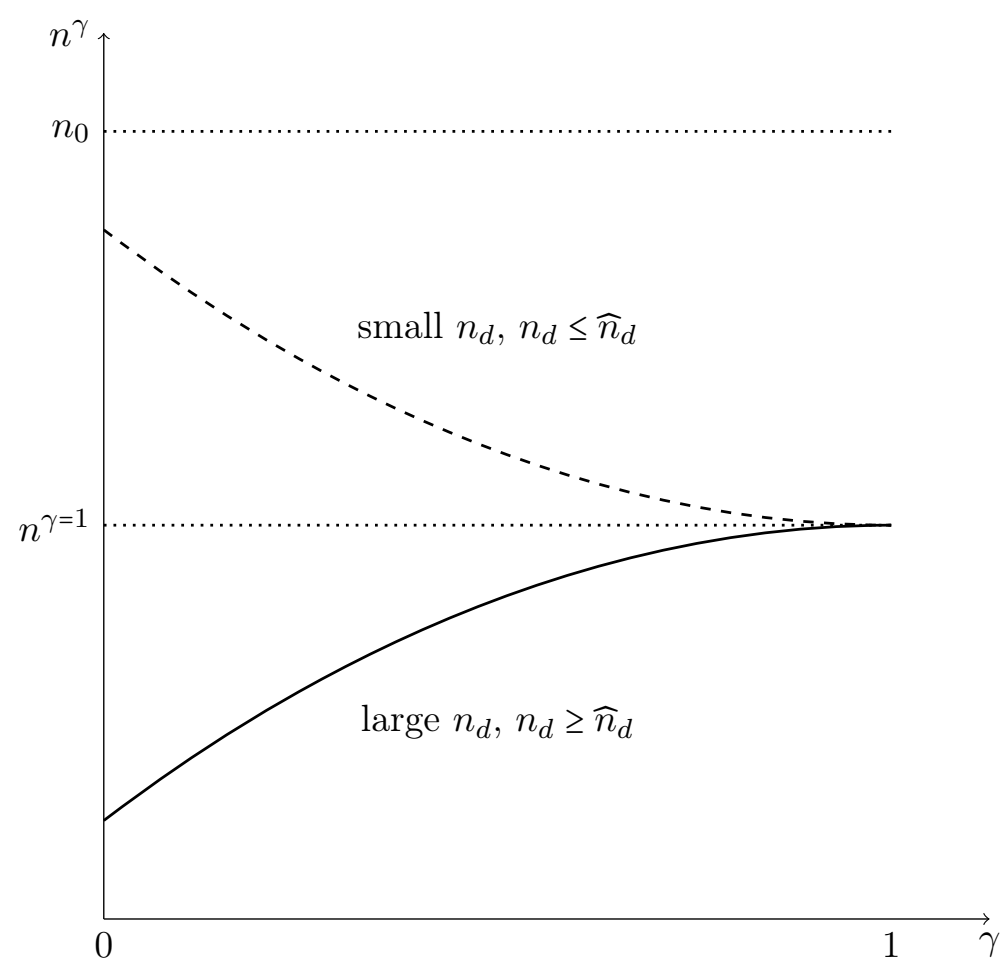

This leads us to the second part of Proposition 3 where both national and foreign firms can lobby. The interesting parameter is here the valuation by the government of a unit of foreign contributions with respect to a unit of national contributions. Figure 3 provides a qualitative representation of point (2.) from Proposition 3. There are two interesting cases that emerge when all firms can lobby. The number of national firms determine how the parameter $\gamma$ affects the policy and whether foreign lobbying is here welfare improving or not compared to national lobbying only. To understand this result, it is useful to remember the previous description of the role of foreign lobbying when only foreign firms can lobby. When the number of national firms is small $\left(n_{d} \leq \widehat{n}_{d}\right)$, the policy decreases in the valuation of foreign contributions. The more foreign contributions are valued by the government, the more restrictive the policy is. Figure 2 is here useful to understand this result. It shows that for a small number of national firms, the 
policy chosen when foreign firms only lobby is lower than the policy chosen when national firms only lobby. Therefore a higher influence of foreign contributions is expected to move the policy closer to the outcome when foreign firms only lobby. This explains why a higher contributions leads to a lower policy outcome, i.e. a more restrictive policy. This opposite happens when the number of national firms is large enough. Figure 2 shows that the foreign policy is higher than the national policy. A higher valuation of foreign contributions increases the policy outcome i.e. leads to a less restrictive policy. Finally the impact of the number of national firms disappear when the government equally values both types of contributions. To conclude a higher valuation of foreign contributions is welfare improving only when the number of national firms is large enough. This is interesting because it shows to which extent allowing foreign firms to lobby the domestic government can be welfare improving or not.

\subsection{Foreign lobbying and commitment}

In this lats part we study the government's decision to commit when foreign firms can lobby. We need first to define the commitment value $\Omega$ when both national and foreign firms can lobby and when foreign contributions can be undervalued. The commitment function of the government defined by $\Omega=G_{0}-G^{\gamma}$ is given by

$$
\begin{aligned}
\Omega= & a W\left(n_{0} \mid K_{0}\right)-a W\left(n^{\gamma} \mid K^{\gamma}\right)-\frac{\sigma_{G}}{\sigma_{N}+\sigma_{G}+\gamma \sigma_{F}}\left[\Pi\left(n^{\gamma}\right)-\Pi\left(n_{0} \mid K^{\gamma}\right)\right] \\
& -\left[\frac{\gamma \sigma_{G}}{\sigma_{N}+\sigma_{G}+\gamma \sigma_{F}}\right]\left[\Pi^{D}\left(n^{\gamma}\right)-\Pi^{D}\left(n_{0} \mid K^{\gamma}\right)\right]
\end{aligned}
$$

Result 1 We can define a bargaining power threshold by $\bar{\sigma}_{G}$ such that $\Omega\left(\bar{\sigma}_{G}\right)=0 . \bar{\sigma}_{G}$ is given by the following equation:

$$
\bar{\sigma}_{G}=\frac{\left[1+(\gamma-1) \sigma_{F}\right]\left[a W\left(n_{0} \mid K_{0}\right)-a W\left(n^{\gamma} \mid K^{\gamma}\right)\right]}{\left[\Pi\left(n^{\gamma}\right)-\Pi\left(n_{0} \mid K^{\gamma}\right)\right]+\gamma\left[\Pi^{f}\left(n^{\gamma}\right)-\Pi^{f}\left(n_{0} \mid K^{\gamma}\right)\right]} \quad \wedge \quad 0 \leq \bar{\sigma}_{G} \leq 1
$$

Proof. See Appendix A.

Given the complexity of the commitment expression, we use numerical solutions to qualitatively assess the impact of our parameter $\gamma$ on the commitment value and the willingness for the government to commit. ${ }^{29}$ Figures 4-6-8 show the policy outcome of the bargaining game for different values of the number of national firms $n_{d}$. First we can notice that a low value of $n_{d}$ leads to a policy decreasing in the valuation fo foreign contributions $\gamma$, whereas a high value of $n_{d}$ leads to a policy increasing in the valuation fo foreign contributions $\gamma$. This illustrates the case (2.) of Proposition 3. For each of this case we plot the value of the commitment function $\Omega$ for three different government's bargaining powers $\left(\sigma_{G}=0.3 / 0.6 / 0.9\right)$. The government chooses to commit when $\Omega \geq 0$.

Compared to (Maggi and Rodriguez-Clare, 1998), we do not only consider the bargaining power as the main determinant of government's commitment but we look at the impact of the valuation

\footnotetext{
${ }^{29}$ We present the results for the following values of the parameters: $A=1, v=0.7, a=0.99$. We add similar results in Annex to show that the key qualitative patterns illustrated in this section are robust.
} 
of foreign contributions. Noncooperative bargaining theory suggests that an agents' bargaining power is higher when she is more patient. To test the theoretical results of (Maggi and RodriguezClare, 1998), Limão and Tovar (2011) posit that the relative bargaining power of the government is lower when the rate of firm exit in that industry is lower. The idea is that firms with a low exit rate discount the future less and are more patient. In this part we suggest another parameter that can affect government's commitments: the valuation of foreign contributions. The figures 5-7-9 suggest that the willingness to commit depends on three parameters: the number of national firms, the bargaining power of the government and the valuation of foreign contributions. Except when the government's bargaining power is very low, the commitment value $\Omega$ decreases in the valuation of foreign contributions. The explanation differs whether we are in the first or second case of point (2.) from Proposition 3. In the case of a decreasing policy outcome (low number of national firms -figures 4 and 6), the welfare $\mathrm{W}$ decreases with a lower policy outcome but the government values more foreign contributions that increase his utility when playing the political game. This can explain why the government is less and less willing to commit for higher valuations of foreign contributions. In the case of an increasing policy outcome (high number of national firms -figures 8), the welfare increases because of a higher policy outcome. This can explain why the government less and less needs to commit. Foreign lobbying reduces the time-inconsistency problem. Figure 8 indeed shows that the government is less likely to commit when foreign lobbying leads to higher policy outcome, i.e. less restrictive policy. The willingness to commit is even lower when the government's bargaining power is high. 
Figure 4: $n^{\gamma}$ for a very small $n_{d}$

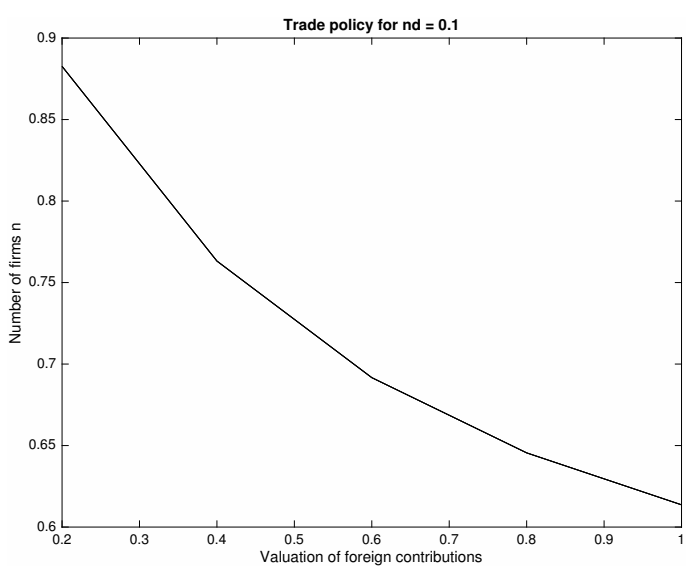

Figure 6: $n^{\gamma}$ for a small $n_{d}$

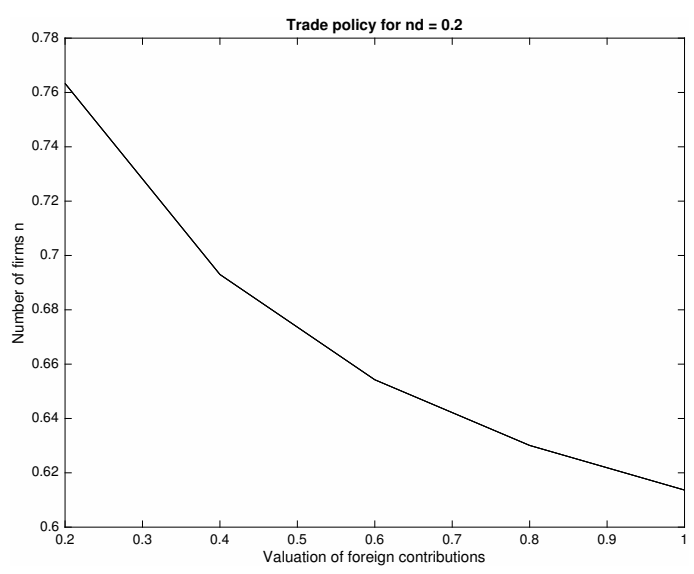

Figure 8: $n^{\gamma}$ for a large $n_{d}$

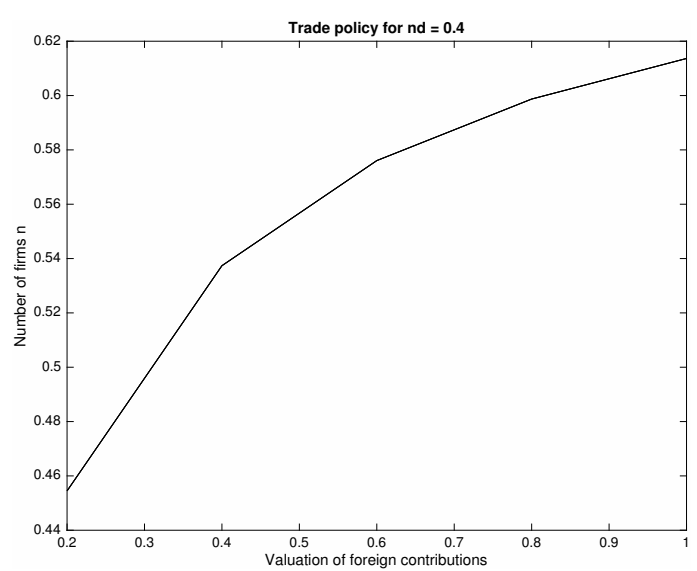

Figure 5: $\Omega=G_{0}-G$ and commitment if $\Omega \geq 0$

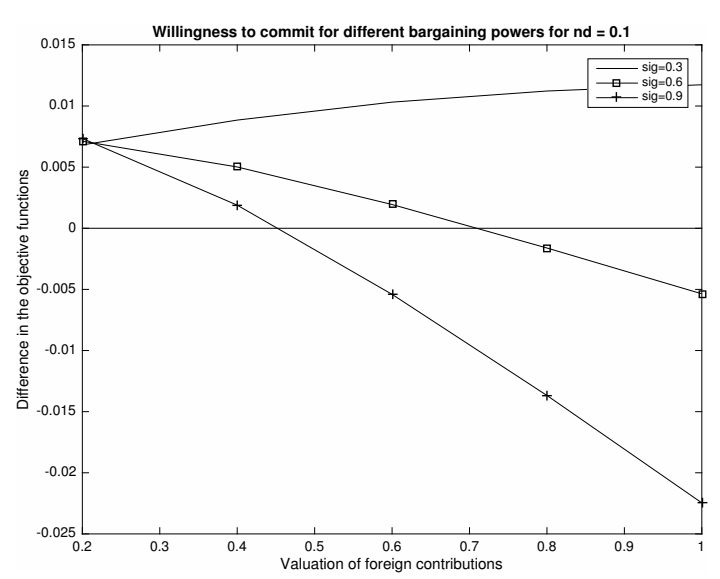

Figure 7: $\Omega=G_{0}-G$ and commitment if $\Omega \geq 0$

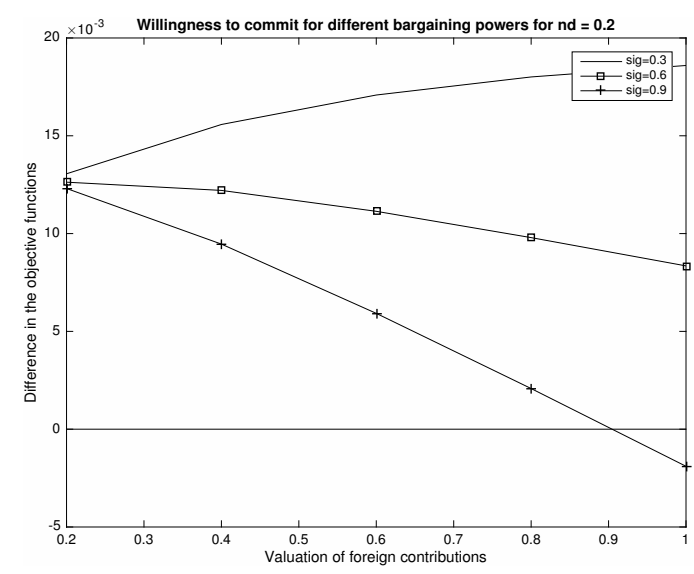

Figure 9: $\Omega=G_{0}-G$ and commitment if $\Omega \geq 0$

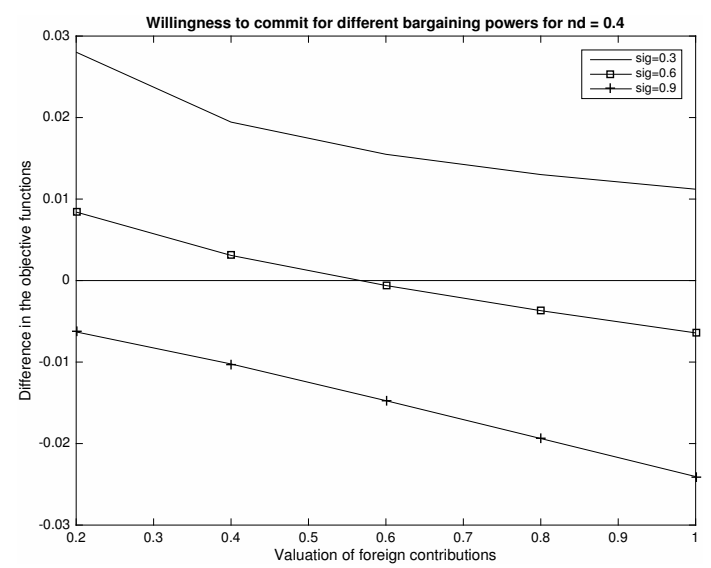




\section{Conclusions}

This paper contributes to the trade policy literature proposing a theory that rationalizes services trade agreements as a commitment device to implement domestic reforms in the services market. Our framework fits to the specificities of services better: their role of complementary inputs, the importance of commercial presence (FDI) and of entry barriers, and the role of trade policies in case of imperfect competition. By extending the basic setting to allow for foreign lobbying that is imperfectly valued by the government, we identify a set of parameters which determine the government's choice to commit. Our model explains the observed low commitment through international services agreements as the consequence of a large national services sector combined with a high valuation of foreign contributions.

Further work should now be done in two directions. First the role of foreign lobbying has been understudied. There is no quantitative cross-country index to reflect the possibility for foreign firms to lobby. It is even more relevant when firms use foreign investment rather than cross-border exports to access foreign markets. Second this paper suggests that the role of services as complement inputs should be considered when explaining services trade policies and commitments in services agreements. More empirical work should be conducted to test services input intensity and their complementarity with other factors of production as determinants of governments commitment to services trade liberalization via international agreements. 


\section{References}

Antràs, Pol and Gerard Padró i Miquel, "Foreign influence and welfare," Journal of International Economics, July 2011, 84 (2), 135-148.

- and Robert W. Staiger, "Offshoring and the Role of Trade Agreements," American Economic Review, 2012, 102 (7), 3140-3183. Published versions have been posted with the written permission of the journals where they appeared. Standard copyright rules apply. Please download and print for personal use only. Robert W. Staiger's website.

Arnold, Jens M., Beata S. Javorcik, and Aaditya Mattoo, "Does services liberalization benefit manufacturing firms? Evidence from the Czech Republic," Journal of International Economics, 2011, 85, 136-146.

_ , _ , and _ , "Services Reform and Manufacturing Performance. Evidence from India," The Economic Journal, forthcoming 2015.

Arnold, Jens Matthias, Aaditya Mattoo, and Gaia Narciso, "Services Inputs and Firm Productivity in Sub-Saharan Africa: Evidence from Firm-Level Data," Journal of African Economies, 2008, 17 (4), 578-599.

Bagwell, Kyle and Robert Staiger, "The economic theory of the GATT," American Economic Review, 1999, pp. 215-248.

Barone, Guglielmo and Federico Cingano, "Service Regulation and Growth: Evidence from OECD Countries," Economic Journal, 09 2011, 121 (555), 931-957.

Beverelli, Cosimo, Matteo Fiorini, and Bernard Hoekman, "Services Trade Restrictiveness and Manufacturing Productivity: the Role of Institutions," CEPR Discussion Paper 10834 September 2015.

Binmore, Ken, Ariel Rubinstein, and Asher Wolinsky, "The Nash Bargaining Solution in Economic Modelling," The RAND Journal of Economics, 1986, 17 (2), 176-188.

Blanchard, Emily, "Reevaluating the role of trade agreements: Does investment globalization make the WTO obsolete?," Journal of International Economics, 2010.

Blanchard, Emily J., "A Shifting Mandate: International Ownership, Global Fragmentation, and a Case for Deeper Integration under the WTO," World Trade Review, 2015, 14 (01), 87-99.

Borchert, Ingo, Batshur Gootiiz, and Aaditya Mattoo, "Policy Barriers to International Trade in Services: Evidence from a New Database," The World Bank Policy Research Working Paper N. 6109 June 2012.

Bourlès, Renaud, Gilbert Cette, Jimmy Lopez, Jacques Mairesse, and Giuseppe Nicoletti, "Do Product Market Regulations in Upstream Sectors Curb Productivity Growth? Panel Data Evidence for OECD Countries," The Review of Economics and Statistics, December 2013, 95 (5), 1750-1768.

Buzard, Kristy, "Trade Agreements in the Shadow of Lobbying," MIMEO 2014. 
Duggan, Victor, Sjamsu Rahardja, and Gonzalo Varela, "Service Sector Reform and Manufacturing Productivity. Evidence from Indonesia," 2013. World Bank Policy Research Working Paper No. 6349.

Egger, Peter and Rainer Lanz, "The Determinants of GATS Commitment Coverage," The World Economy, 2008, 31 (12), 1666-1694.

Epifani, Paolo and Gino Gancia, "Trade, markup heterogeneity and misallocations," Journal of International Economics, 2011, 83 (1), 1 - 13.

Fernandes, Ana and Caroline Paunov, "Foreign Direct Investment in Services and Manufacturing Productivity: Evidence for Chile," Journal of Development Economics, 2011, 97 (2), 305-321.

Francois, Joseph and Bernard Hoekman, "Services Trade and Policy," Journal of Economic Literature, 2010, 48 (3), 642-692.

Francois, Joseph F., "Producer Services, Scale, and the Division of Labor," Oxford Economic Papers, 1990, 42 (4), 715-729.

_, "Trade in Producer Services and Returns due to Specialization under Monopolistic Competition," The Canadian Journal of Economics, 1990, 23 (1), 109-124.

Fung, K. C. and Alan Siu, "Political Economy of Service Trade Liberalization and the Doha Round," Pacific Economic Review, 2008, 13 (1), 124-133.

Gawande, Kishore, Pravin Krishna, and Michael J. Robbins, "Foreign Lobbies and U.S. Trade Policy," The Review of Economics and Statistics, 2006, 88 (3), 563-571.

Grossman, Gene and Elhanan Helpman, "Protection for Sale," American Economic Review, September 1994, 84, 833-850.

Hoekman, Bernard, "The General Agreement on Trade in Services: Doomed to Fail? Does it Matter?," Journal of Industry, Competition and Trade, 2008, 8 (3), 295-318.

- and Benjamin Shepherd, "Services Productivity, Trade Policy, and Manufacturing Exports," The World Economy, forthcoming 2015.

Javorcik, Beata, Wolfgang Keller, and James Tybout, "Openness and Industrial Response in a Wal-Mart World: A Case Study of Mexican Soaps, Detergents and Surfactant Producers," The World Economy, 2008, 31 (12), 1558-1580.

Jensen, J.Bradford, Global Trade in Services: Fear, Facts, and Offshoring, Peterson Institute for International Economics, 2011.

Limão, Nuno and Patricia Tovar, "Policy choice: Theory and evidence from commitment via international trade agreements," Journal of International Economics, 2011, 85 (2), 186-205.

Maggi, Giovanni and Andres Rodriguez-Clare, "The Value of Trade Agreements in the Presence of Political Pressures," Journal of Political Economy, 1998, 106 (3), 574-601. 
Markusen, James, Thomas F. Rutherford, and David Tarr, "Trade and direct investment in producer services and the domestic market for expertise," Canadian Journal of Economics/Revue canadienne d'économique, 2005, 38 (3), 758-777. 


\section{Appendices}

\section{A Proofs and Derivations}

Efficiency of the Nash Solution We want to show that the Nash solution of the cooperative bargaining game - given by (3.19) - maximises the joint surplus (3.20). Let's start off deriving the first order condition (FOC) from the maximisation of the joint surplus

$$
\frac{\mathrm{d} \mathbb{J}^{N}(n)}{\mathrm{d} n}=0 \Longleftrightarrow \underbrace{a \frac{\mathrm{d} W(n)}{\mathrm{d} n}}_{X}=-\underbrace{n_{d} \frac{\mathrm{d} \pi^{S}(n)}{\mathrm{d} n}}_{Y}
$$

Instead, the FOCs for the Nash product maximisation are given by

$$
\begin{gathered}
\text { w. r. to } n: \quad \sigma X\left[n_{d} \pi^{S}(n)-c-n_{d} \pi^{S}\left(n_{0}\right)\right]+(1-\sigma) Y\left[a W(n)+c-a W\left(n_{0}\right)\right]=0 \\
\text { w. r. to } c: \quad c=\sigma n_{d}\left[\pi^{S}(n)-\pi^{S}\left(n_{0}\right)\right]+(1-\sigma) a\left[W\left(n_{0}\right)-W(n)\right]
\end{gathered}
$$

Plugging (A-3) into (A-2) and rearranging we get

$$
\begin{aligned}
& {\left[W\left(n_{0}\right)-W(n)\right] \times \overbrace{[-(1-\sigma)(\sigma a) Y-(1-\sigma)(\sigma a) X]}^{Z}+} \\
& +\left[\pi^{S}(n)-\pi^{S}\left(n_{0}\right)\right] \times \underbrace{\left[(1-\sigma) \sigma n_{d} Y+(1-\sigma) \sigma n_{d} X\right]}_{V}=0
\end{aligned}
$$

Plugging the efficiency condition $X=-Y$ into (A-4) we get $Z=V=0$. The unique Nash solution of the bargaining game is therefore efficient (unicity is stated in Proposition 1).

Proof of Proposition 1. Equilibrium prices - $\left(P^{D}\right)^{N}$ and $\left(P^{S}\right)^{N}-$ as well as $K^{N}$ can be uniquely determined as functions of trade policy $n$. In particular

$$
\begin{gathered}
P^{D}=v-f(n A) \\
P^{S}=[v-f(n A)] f^{\prime}(n A) \\
K^{N}=n A
\end{gathered}
$$

Plugging those expressions into the social welfare and the profit functions we get an expression of the Nash product as a function of $n$ and $c$, plus exogenous parameters. The FOC with respect to $n$ of the Nash product maximisation problem (3.19) is given by

$$
\left(a-2 n_{d}\right) e^{-2 n}=(1-v)\left(a-n_{d}\right) e^{-n}
$$

Taking logs and solving for $n$ we get the equilibrium trade policy

$$
n^{N}=-\ln \left(\frac{(1-v)\left(a-n_{d}\right)}{a-2 n_{d}}\right)
$$

For the equilibrium solution $n^{N}=-\ln \left(\frac{(1-v)\left(a-n_{d}\right)}{a-2 n_{d}}\right)$ to be well defined, we need to find the parameters for which $n^{N}$ is smaller than the trade policy implemented in the absence of special interest groups. Indeed the domestic services firms give contributions to the government to lower the number of final firms with respect to the government optimal solution without distorting political pressures. In other words, the national lobby would not contribute for a number of 
firms higher than the level chosen in the case of no lobbying. The optimal value of $n$ chosen in the absence of political pressures is given by $n_{0}=-\ln (1-v)$. We can rewrite $n^{N}$ as follows

$$
n^{N}=n_{0}-\ln \left(\frac{a-n_{d}}{a-2 n_{d}}\right)
$$

The equilibrium under national lobby is well defined if $n^{N}<n_{0}$, i.e. if

$$
\frac{a-n_{d}}{a-2 n_{d}}>1 \Longleftrightarrow n_{d}<\frac{a}{2}
$$

Condition (A-11) defines the technical restrictions on the parameters which are needed to have an equilibrium solution with positive contributions.

Turning to the last equilibrium quantity, $c^{N}$, it can be uniquely determined as a function of $n$ and exogenous parameters from the Nash product maximisation problem (3.19). The FOC with respect to $c$ gives the usual weighted average of the welfare loss from protection and the lobby's willingness to pay for protection

$$
c^{N}=(1-\sigma) a\left[W\left(n_{0}\right)-W\left(n^{N}\right)\right]+\sigma n_{d}\left[\pi^{S}\left(n^{N}\right)-\pi^{S}\left(n_{0}\right)\right]
$$

Equations (A-5), (A-6), (A-7), (A-9) and (A-12) uniquely define the equilibrium under national lobbying. The equilibrium is well defined under the technical restriction given in (A-11).

The comparative statics results are given by the study of the partial derivatives of $n^{N}$ that completes the proof

$$
\begin{aligned}
& \frac{\partial n^{N}}{\partial a}=\frac{n_{d}}{\left(a-n_{d}\right)\left(a-2 n_{d}\right)} \geq 0 \\
& \frac{\partial n^{N}}{\partial n_{d}}=\frac{-a}{\left(a-n_{d}\right)\left(a-2 n_{d}\right)} \leq 0
\end{aligned}
$$

Proof of Proposition 2. Let us start from (i). We want to show that $\Omega(\sigma=0)>0$ where

$$
\Omega=G_{0}-G^{N}=a W\left(n_{0}, K_{0}\right)-a W\left(n^{N}, K^{N}\right)-c^{N}
$$

The equilibrium condition given by the FOC of the Nash product maximisation with respect to $c$ gives

$$
a W\left(n^{N}, K^{N}\right)+c^{N}-a W\left(n_{0}, K^{N}\right)=\frac{\sigma}{1-\sigma}\left[\Pi^{S}\left(n^{N}, K^{N}\right)-c^{N}-\Pi^{S}\left(n_{0}, K^{N}\right)\right]
$$

which can be rearranged to get

$$
c^{N}+a W\left(n^{N}, K^{N}\right)=\sigma\left[\Pi^{S}\left(n^{N}, K^{N}\right)-\Pi\left(n_{0}, K^{N}\right)\right]+a \sigma W\left(n^{N}, K^{N}\right)+a(1-\sigma) W\left(n_{0}, K^{N}\right)
$$

Plugging (A-17) into (A-15) we get

$\Omega=a W\left(n_{0}, K_{0}\right)-a W\left(n_{0}, K^{N}\right)-\sigma\left[\Pi^{S}\left(n^{N}, K^{N}\right)-\Pi\left(n_{0}, K^{N}\right)\right]+\sigma a\left[W\left(n_{0}, K^{N}\right)-W\left(n^{N}, K^{N}\right)\right]$

Therefore, with $\sigma=0$ we have

$$
\Omega(\sigma=0)=a W\left(n_{0}, K_{0}\right)-a W\left(n_{0}, K^{N}\right)
$$

Consider the equilibrium result $D^{S}\left(n_{0}, K^{N}\right)=K^{N}$. This allows us to write $f\left(K^{N}, D^{S}\left(n_{0}, K^{N}\right)\right)=$ 
$f\left(K^{N}, K^{N}\right):=f\left(K^{N}\right)$. We can now write the welfare

$$
W\left(n_{0}, K^{N}\right)=\left(v-f\left(K^{N}\right)\right) f\left(K^{N}\right)+H\left(v-f\left(K^{N}\right)\right)
$$

Similarly we use the equilibrium result $D^{S}\left(n_{0}, K_{0}\right)=K_{0}$ to write $f\left(K_{0}, D^{S}\left(n_{0}, K_{0}\right)\right)=f\left(K_{0}, K_{0}\right):=$ $f\left(K_{0}\right)$. Therefore

$$
W\left(n_{0}, K_{0}\right)=\left(v-f\left(K_{0}\right)\right) f\left(K_{0}\right)+H\left(v-f\left(K_{0}\right)\right)
$$

Define the function $g(x)$ by $g(x)=(v-f(x)) f(x)+h(v-f(x))$ with $H(x)=(v-x)^{2} / 2$. Taking the derivative of $g$ we get $g^{\prime}(x)=f^{\prime}(x)(v-f(x))>0$. Moreover we know that $K^{N}<K_{0}$. Therefore $W\left(n_{0}, K_{0}\right)-W\left(n_{0}, K^{N}\right)>0$, which completes the proof of (i).

We now move to (ii). We can express $\Omega$ as a linear function of $\sigma$ of the kind $\Omega(\sigma)=Y \sigma+Z$. Start from the expression for $\Omega$ given by (A-18). First we show that $W\left(n_{0}, K^{N}\right)-W\left(n^{N}, K^{N}\right)=0$. To see this we use the result $D^{S}\left(n_{0}, K^{N}\right)=K^{N}$ that allows us to write $f\left(K^{N}, D^{S}\left(n_{0}, K^{N}\right)\right)=$ $f\left(K^{N}, K^{N}\right):=f\left(K^{N}\right)$. We can now write the welfare

$$
W\left(n_{0}, K^{N}\right)=\left(v-f\left(K^{N}\right)\right) f\left(K^{N}\right)+H\left(v-f\left(K^{N}\right)\right)
$$

Similarly we use the equilibrium result $D^{S}\left(n^{N}, K^{N}\right)=K^{N}$ to write $f\left(K^{N}, D^{S}\left(n^{N}, K^{N}\right)\right)=$ $f\left(K^{N}, K^{N}\right):=f\left(K^{N}\right)$. Therefore

$$
W\left(n^{N}, K^{N}\right)=\left(v-f\left(K^{N}\right)\right) f\left(K^{N}\right)+H\left(v-f\left(K^{N}\right)\right)
$$

We conclude that $W\left(n_{0}, K^{N}\right)=W\left(n^{N}, K^{N}\right)$. Given this we have $\Omega(\sigma)=Y \sigma+Z$ with

$$
Y=-\left[\Pi^{S}\left(n^{N}, K^{N}\right)-\Pi^{S}\left(n_{0}, K^{N}\right)\right]
$$

and

$$
Z=a W\left(n_{0}, K_{0}\right)-a W\left(n_{0}, K^{N}\right)(>0)
$$

We show that $Y<0$. Given the equilibrium expressions for prices we can write

$$
\begin{gathered}
\pi^{S}\left(n^{N}, K^{N}\right)=A\left(P^{D}\right)^{N} f^{\prime}\left(K^{N}\right) \\
\pi^{S}\left(n_{0}, K^{N}\right)=\frac{K^{N}}{n_{0}} P^{D}\left(n_{0}, K^{N}\right) f^{\prime}\left(K^{N}\right)=\frac{K^{N}}{n_{0}}\left(P^{D}\right)^{N} f^{\prime}\left(K^{N}\right)
\end{gathered}
$$

the second equality comes from the following

$$
P^{D}\left(n_{0}, K^{N}\right)=v-f\left(K^{N}, D^{S}\left(n_{0}, K^{N}\right)\right)=v-f\left(K^{N}\right)=\left(P^{D}\right)^{N}
$$

We can now write the slope $Y$.

$$
\begin{aligned}
Y & =-n_{d}\left[\pi^{S}\left(n^{N}, K^{N}\right)-\pi^{S}\left(n_{0}, K^{N}\right)\right] \\
& =-n_{d}\left[A-\frac{K^{N}}{n_{0}}\right]\left(P^{D}\right)^{N} f^{\prime}\left(K^{N}\right) \text { with } K^{N}=A n^{N} \\
& =-n_{d} A\left[1-\frac{n^{N}}{n_{0}}\right]\left(P^{D}\right)^{N} f^{\prime}\left(K^{N}\right)
\end{aligned}
$$

Given that $n^{N}<n_{0}$ and $f^{\prime}\left(K^{N}\right)>0$ we can conclude that $Y<0$.

From this we can define $\widetilde{\sigma}$ such that $\Omega(\widetilde{\sigma})=0$ and

$$
\widetilde{\sigma}=\frac{-Z}{Y}
$$


We want to find the parameters $a, n_{d}, v$ for which $\frac{-Z}{Y}<1$.

Using the results $n^{N}=-\ln \left(\frac{(1-v)\left(a-n_{d}\right)}{a-2 n_{d}}\right)$ and $n_{0}=-\ln (1-v)$ we have:

$$
\begin{gathered}
Y=(v-1)\left[n_{d} \frac{\ln \left(\frac{a-n_{d}}{a-2 n_{d}}\right)}{\ln (1-v)}\right]\left[\frac{(1-v)\left(a-n_{d}\right)}{a-2 n_{d}}\right]+\left[n_{d} \frac{\ln \left(\frac{a-n_{d}}{a-2 n_{d}}\right)}{\ln (1-v)}\right]\left[\frac{(1-v)\left(a-n_{d}\right)}{a-2 n_{d}}\right]^{2} \\
Z=\frac{a(v-1)^{2}}{2}+(v-1) a\left[\frac{(1-v)\left(a-n_{d}\right)}{a-2 n_{d}}\right]+[a / 2]\left[\frac{(1-v)\left(a-n_{d}\right)}{a-2 n_{d}}\right]^{2}
\end{gathered}
$$

which imply

$$
\begin{array}{r}
\Omega=\frac{a(v-1)^{2}}{2}+(v-1)\left[a+\sigma n_{d} \frac{\ln \left(\frac{a-n_{d}}{a-2 n_{d}}\right)}{\ln (1-v)}\right]\left[\frac{(1-v)\left(a-n_{d}\right)}{a-2 n_{d}}\right]+ \\
+\left[a / 2+\sigma n_{d} \frac{\ln \left(\frac{a-n_{d}}{a-2 n_{d}}\right)}{\ln (1-v)}\right]\left[\frac{(1-v)\left(a-n_{d}\right)}{a-2 n_{d}}\right]^{2}
\end{array}
$$

To simplify the expression, we write $X=\frac{(1-v)\left(a-n_{d}\right)}{a-2 n_{d}}$ and $C=-n_{d} \frac{\ln \left(\frac{a-n_{d}}{a-2 a n_{d}}\right)}{\ln (1-v)}$. Therefore we have $-Z=\frac{a}{2} X^{2}+a(v-1) X+a \frac{(v-1)^{2}}{2}$ and $Y=C\left[X(v-1)+X^{2}\right]$. We want to find the parameters for which : $\frac{-Z}{Y}<1$.

After some algebra we get

$$
\widetilde{\sigma}=\frac{-Z}{Y}=\frac{\ln (1-v)}{2 \ln \left(\frac{a-n_{d}}{a-2 n_{d}}\right)\left(n_{d}-a\right)}
$$

notice that both the numerator and the enumerator of the above expression are strictly smaller than 0 , therefore $\frac{-Z}{Y}<1$ if and only if

$$
\ln (1-v)>2 \ln \left(\frac{a-n_{d}}{a-2 n_{d}}\right)\left(n_{d}-a\right)
$$

Notice that the LHS of (A-36) is a monotonically decreasing function of $v$ while the RHS of (A-36) is constant with respect to $v$. Therefore there exists unique a threshold value $V$ such that $\forall v<V$ inequality (A-36) is verified. It is easy to get the expression

$$
V=1-\exp \left[2 \ln \left(\frac{a-n_{d}}{a-2 n_{d}}\right)\left(n_{d}-a\right)\right]
$$

Notice that $V \in(0,1)$. We conclude that, fixing any pair $\left(a, n_{d}\right) \in \mathbb{R}^{+} \times \mathbb{R}^{+}$that verify the regularity condition $n_{d}<a / 2$, for any $v<V, \widetilde{\sigma}<1$, therefore $\exists$ ! $\bar{\sigma}(=\widetilde{\sigma}) \in(0,1)$ such that $\Omega(\bar{\sigma})=0$. Since we have already shown that $\Omega$ is monotonically decreasing is $\sigma$ the proof is complete.

Proof of Part 1 of Proposition 3. The proof of this part is similar to the proof of proposition 1. We use the expressions of optimal prices and investment in non-services inputs. Once we prove the existence and unicity of the equilibrium policy, we can easily derive the other equilibrium variables and obtain the existence and unicity of the whole equilibrium.

The policy maximizes the Nash product such that

$$
\begin{aligned}
& a W^{\prime}\left(n^{\gamma}\right)+\mathbb{I} \pi^{\prime}\left(n^{\gamma}\right)+\gamma\left(n^{\gamma}-n_{d}\right) \pi^{\prime}\left(n^{\gamma}\right)=0 \\
\Rightarrow & a\left[\left(v-f\left(n^{\gamma}\right)\right) f^{\prime}\left(n^{\gamma}\right)\right]+\mathbb{I}\left[v-f\left(n^{\gamma}\right)\right] f^{\prime}\left(n^{\gamma}\right)-\left(n^{\gamma}-n_{d}\right)\left(f^{\prime}\left(n^{\gamma}\right)+v-f\left(n^{\gamma}\right)\right)=0 \\
\Rightarrow & n^{\gamma}=-\ln \left(\frac{(1-v)\left(a+\gamma-\gamma n^{\gamma}-(\mathbb{I}-\gamma) n_{d}\right)}{\left(a+\gamma-2 \gamma n^{\gamma}-2(\mathbb{I}-\gamma) n_{d}\right)}\right)
\end{aligned}
$$


Parameters are restricted so that the solution is well defined. The necessary condition is given by:

$$
a+\gamma-2 \gamma n^{\gamma}-2(\mathbb{I}-\gamma) n_{d}>0 \quad \Rightarrow \quad n^{\gamma}<\frac{a+\gamma-2(\mathbb{I}-\gamma) n_{d}}{2 \gamma}
$$

The solution is on both sides of the equation. We need to prove that there exists a unique solution $n^{\gamma}$ which is well-defined by the previous equation. First we define a new function $\mathrm{g}$ with two variables $\gamma$ with $\gamma \geq 0$ and $n^{\gamma}$ such that

$$
g\left(\gamma, n^{\gamma}\right)=-\ln (\overbrace{\frac{(1-v)\left(a+\gamma-\gamma n^{\gamma}-(\mathbb{I}-\gamma) n_{d}\right)}{\underbrace{\left(a+\gamma-2 \gamma n^{\gamma}-2(\mathbb{I}-\gamma) n_{d}\right)}_{D}}}^{N})
$$

The solution $n^{\gamma}$ to the Nash product maximization is such that $g\left(\gamma, n^{\gamma}\right)=n^{\gamma}$. We have:

$$
\frac{\partial g}{\partial n^{\gamma}}=-\frac{D}{N} \frac{-\gamma D-N(-2 \gamma)}{D^{2}}=-\frac{\gamma(a+\gamma)}{N D} \Rightarrow \frac{\partial g}{\partial n^{\gamma}}<0
$$

The condition $N D>0$ is given by the previous restriction on parameters for the solution to be defined. We can now prove the existence and unicity. The function Identity $(n \rightarrow n)$ is strictly increasing and starts at 0 and goes towards infinity. In addition for any $\gamma$, the function $g(\gamma,$. is strictly decreasing in its second argument $\mathrm{n}$ and $g(\gamma, 0)>0$. This implies the existence of the solution $n^{\gamma}$ and its unicity.

Proof of Part 2 of Proposition 3. We restrict our analysis to the case of foreign lobbying only $(\mathbb{I}=0)$ and perfect valuation of foreign contributions $(\gamma=1)$. We can show the existence of the threshold $n_{d}^{=}$and the following implications.

First we find the expression of $n_{d}^{=}$which is defined by the number of domestic firms $n_{d}$ such that the policy $n^{N}$ when there is national lobbying only (defined in 1 ) is equal to the policy $n^{\gamma}(\mathbb{I}=0)$ when there is foreign lobbying only.

$$
\begin{aligned}
n^{N}=n^{\gamma}(\mathbb{I}=0) & \Rightarrow-\ln \left(\frac{(1-v)\left(a-n_{d}^{=}\right)}{a-2 n_{d}^{=}}\right)=-\ln \left(\frac{(1-v)\left(1+a-\left(n^{f}-n_{d}^{=}\right)\right)}{\left(1+a-2\left(n^{f}-n_{d}^{=}\right)\right)}\right) \\
& \Rightarrow n^{\gamma}(\mathbb{I}=0)=n_{d}^{=} \frac{1+2 a}{a}
\end{aligned}
$$

We plug this expression in the previous equality

$$
n^{\gamma}(\mathbb{I}=0)=n^{N} \Rightarrow n_{d}^{=} \frac{1+2 a}{a}=-\ln \left(\frac{(1-v)\left(a-n_{d}^{\bar{\nu}}\right)}{a-2 n_{d}^{\bar{y}}}\right)
$$

The threshold for which the two policies are equal exist if the equation $g(x)=-\frac{a}{1+2 a} \ln \left(\frac{(1-v)(a-x)}{a-2 x}\right)-$ $x=0$ has a solution. We use equation A-13 from the proof of proposition 1 to show that the function $\mathrm{g}$ is strictly decreasing. In addition $g(0)>0$ and $g(+\infty)=-\infty$. This shows that there exists a unique threshold $n_{d}^{=}$for which $n^{N}=n^{\gamma}(\mathbb{I}=0)$.

We have proved that $n^{N}$ is strictly decreasing in $n_{d}$ (equation A-13). We can show that $n^{\gamma}(\mathbb{I}=0$ ) is strictly increasing in $n_{d}$. We derive the expression of $n^{\gamma}(\mathbb{I}=0)$ in Proposition 3 with respect 
to $n_{d}$.

$$
\begin{aligned}
& \frac{\partial n^{\gamma}(\mathbb{I}=0)}{\partial n_{d}}+\frac{1+a-2\left(n^{\gamma}(\mathbb{I}=0)-n_{d}\right)}{1+a-n^{\gamma}(\mathbb{I}=0)+n_{d}} \times \\
& \times \frac{\left(-\frac{\partial n^{\gamma}(\mathbb{I}=0)}{\partial n_{d}}+1\right)\left(1+a-2\left(n^{\gamma}(\mathbb{I}=0)-n_{d}\right)\right)-\left(1+a-n^{\gamma}(\mathbb{I}=0)+n_{d}\right)\left(-2 \frac{\partial n^{\gamma}(\mathbb{I}=0)}{\partial n_{d}}+2\right)}{\left(1+a-2\left(n^{\gamma}(\mathbb{I}=0)-n_{d}\right)\right)^{2}}=0 \\
\Rightarrow \quad & {\left[1+\frac{1+a}{\left(1+a-2\left(n^{\gamma}(\mathbb{I}=0)-n_{d}\right)\right)\left(1+a-n^{\gamma}(\mathbb{I}=0)+n_{d}\right)}\right] \frac{\partial n^{\gamma}(\mathbb{I}=0)}{\partial n_{d}} } \\
\quad & \frac{1+a}{\left(1+a-2\left(n^{\gamma}(\mathbb{I}=0)-n_{d}\right)\right)\left(1+a-n^{\gamma}(\mathbb{I}=0)+n_{d}\right)} \\
\Rightarrow & \frac{\partial n^{\gamma}(\mathbb{I}=0)}{\partial n_{d}} \geq 0
\end{aligned}
$$

This shows that the policy $n^{\gamma}(\mathbb{I}=0)$ is decreasing in the number of domestic firms $n_{d}$. Therefore We can prove the second part of Proposition 3. When the number of domestic firms is small $\left(n_{d} \leq n_{d}^{=}\right)$, we have $n^{N} \geq n^{f}$ and the opposite $n^{N} \leq n^{f}$ when the number of domestic firms is large $\left(n_{d} \geq n_{d}^{=}, n^{N} \leq n^{f}\right)$.

\section{Proof of Part 3 of Proposition 3.}

In this part we allow for both national and foreign contributions given that foreign contributions are less valued than national contributions $(\mathbb{I}=1$ and $0 \leq \gamma \leq 1)$. First we study how the policy $n^{\gamma}$ varies with the responsiveness $\gamma$ of the government to foreign contributions. Second we determine when the policy with both foreign and national lobbying $\left(n^{\gamma}\right)$ is higher than the one chosen in case of no foreign lobbying $\left(n^{N}\right)$.

First we study how the solution $n^{\gamma}$ varies with the responsiveness $\gamma$ of the government to foreign contributions. Let's recall the expression of the policy in the case of $\mathbb{I}=1$ and $0 \leq \gamma \leq 1$.

$$
n^{\gamma}=-\ln (\overbrace{\frac{(1-v)\left(a+\gamma-\gamma n^{\gamma}-(1-\gamma) n_{d}\right)}{\underbrace{\left(a+\gamma-2 \gamma n^{\gamma}-2(1-\gamma) n_{d}\right)}_{D}}}^{N})
$$

We derive the previous equation with respect to $\gamma$.

$$
\begin{aligned}
& \frac{\partial n^{\gamma}}{\partial \gamma}+\frac{D}{N} \frac{\left[1-n^{\gamma}-\gamma \frac{\partial n^{\gamma}}{\partial \gamma}+n_{d}\right] D-N\left[1-2 n^{\gamma}-2 \gamma \frac{\partial n^{\gamma}}{\partial \gamma}+2 n_{d}\right]}{D^{2}}=0 \\
\Rightarrow & {\left[1+\gamma \frac{a+\gamma}{N D}\right] \frac{\partial n^{\gamma}}{\partial \gamma}=\frac{(1+a) n_{d}-a n^{\gamma}}{N D} } \\
\Rightarrow & \operatorname{Sign}\left(\frac{\partial n^{\gamma}}{\partial \gamma}\right)=\operatorname{Sign}\left((1+a) n_{d}-a n^{\gamma}\right)
\end{aligned}
$$

given that $N D \geq 0$ for the solution to be well-defined.

There are two cases that emerge:

1. if $(1+a) n_{d}-a n^{\gamma}>0$ then $\frac{\partial n^{\gamma}}{\partial \gamma}>0$

2. if $(1+a) n_{d}-a n^{\gamma}<0$ then $\frac{\partial n^{\gamma}}{\partial \gamma}<0$

We do not have a closed-form solution for $n^{\gamma}$ with $\gamma>0$. The following part shows that we can still determine the parameters for which $n^{\gamma}$ is either decreasing or increasing in $\gamma$. First we look 
at the $n^{\gamma}$ in the neighbourhood of $\gamma=0$ and the closed-form solution for $n^{\gamma=0}=n^{N}$ is given in Proposition 1. Second we infer conclusions on the monotonicity of the solution $n^{\gamma}$ with respect to $\gamma$.

Let's start in the neighbourhood of $\gamma=0$ and consider the case (1) where $n^{\gamma=0}<\frac{(1+a)}{a} n_{d}$. First we consider a small neighbourhood $V=[0, v]$ such that for all $\gamma \in V$ the solution $n^{\gamma}$ remains inferior to $\frac{(1+a) n_{d}}{a}{ }^{30}$ Then $\forall n^{\gamma}$ that corresponds to a $\gamma$ in the neighbourhood $V$, the policy is decreasing with respect of $\gamma\left(\frac{\partial n^{\gamma}}{\partial \gamma}>0\right.$ from the previous result). Second we show by contradiction that $\forall \gamma \geq 0, n^{\gamma}<\frac{(1+a)}{a} n_{d}$. We assume that there exists a parameter $\gamma_{2}$ for which $n^{\gamma_{2}}>\frac{(1+a)}{a} n_{d}$. We are in the case where in the neighbourhood of $\gamma=0, n^{\gamma=0}<\frac{(1+a)}{a} n_{d}$. By continuity of the solution $n^{\gamma}$ and using the theorem of intermediate values, there exists a $\gamma_{1}<\gamma_{2}$ such that $n^{\gamma_{1}}=\frac{(1+a)}{a} n_{d}$. Therefore we have $\gamma_{1}<\gamma_{2}$ and $n^{\gamma_{2}}>\frac{(1+a)}{a} n_{d}=n^{\gamma_{1}}$. This contradicts the result that $\frac{\partial n^{\gamma}}{\partial \gamma}<0$ for $n^{\gamma}>\frac{(1+a)}{a} n_{d}$. To conclude, we just proved that when $n^{\gamma=0}<\frac{(1+a)}{a} n_{d}$ then $\forall \gamma \geq 0, n^{\gamma}<\frac{(1+a)}{a} n_{d}$ and $n^{\gamma}$ increases in $\gamma$. Similarly we can show that when $n^{\gamma=0}>\frac{(1+a)}{a} n_{d}, \forall \gamma \geq 0, n^{\gamma}>\frac{(1+a)}{a} n_{d}$ and $n^{\gamma}$ decreases in $\gamma$.

Given that we have the closed-form solution of $n^{\gamma=0}$, we can now determine the parameters for which $n^{\gamma=0}<\frac{(1+a)}{a} n_{d}$ and $n^{\gamma}$ increases in $\gamma$. We have that

$$
n^{\gamma=0}<\frac{(1+a)}{a} n_{d} \quad \Rightarrow \quad-\ln \left(\frac{(1-v)\left(a-n_{d}\right)}{a-2 n_{d}}\right)<\frac{(1+a)}{a} n_{d}
$$

We define a function $g$ such that $g(n)=\frac{(1-v)(a-n)}{a-2 n}-\exp \left(-\frac{(1+a)}{a} n\right)$. This function is shown to be increasing $\left(\forall n, f^{\prime}(n)=\frac{(1-v) a}{(1-2 a n)^{2}}+(1+a) e^{-\frac{(1+a)}{a} n} \geq 0\right)$ if $n \leq \frac{a}{2}$. The latter constraint is the regularity condition $\left(n_{d} \leq \frac{a}{2}\right)$ that has restricted our analysis for the existence proof in Proposition 1. In addition $g(0)=-v<0$ and $g\left(\frac{a}{2}\right)=\infty>0$. We then use the theorem of intermediate values to show that there exists a $\tilde{n_{d}}>0$ such that:

1. if $n_{d} \leq \tilde{n_{d}}$ then $g\left(n_{d}\right) \leq 0$ and $n^{\gamma=0} \geq \frac{(1+a)}{a} n_{d}$. This defines the interval $S^{-}=\left[0, \tilde{n_{d}}\right]$.

2. if $n_{d} \geq \tilde{n_{d}}$ then $g\left(n_{d}\right) \geq 0$ and $n^{\gamma=0} \leq \frac{(1+a)}{a} n_{d}$. This defines the interval $S^{+}=\left[\tilde{n_{d}}, \frac{1}{2 a}\right]$.

We can now conclude that:

1. when the number of domestic firms $n_{d}$ is low: $n_{d} \in S^{-}$
(a) $n^{\gamma=0} \geq \frac{(1+a)}{a} n_{d}$
(b) $\forall \gamma>0, n^{\gamma} \leq n^{\gamma=0}=n^{N}$
(c) $\frac{\partial n^{\gamma}}{\partial \gamma} \leq 0$

2. when the number of domestic firms $n_{d}$ is large : $n_{d} \in S^{+}$
(a) $n^{\gamma=0} \leq \frac{(1+a)}{a} n_{d}$
(b) $\forall \gamma>0, n^{\gamma} \geq n^{\gamma=0}=n^{N}$
(c) $\frac{\partial n^{\gamma}}{\partial \gamma} \geq 0$

Proof of Result 1 The bargaining game leads to the maximization of the Nash product from equation 4.3. It implies that contributions are defined in order to allocate the joint surplus

\footnotetext{
${ }^{30}$ The proof of the existence of such neighbourhood is given by the continuity of $n^{\gamma}$.
} 
according to each bargaining power. We first find the expressions of the two contributions to plug them into the utility of the government while playing the political game.

$$
\left\{\begin{array}{r}
a W\left(n^{\gamma}\right)+c^{\gamma}+\gamma c^{f, \gamma}-a W\left(n_{0} \mid K^{\gamma}\right)=\sigma_{G} \mathbb{J} \\
\Pi\left(n^{\gamma}\right)-c^{\gamma}-\Pi\left(n_{0} \mid K^{\gamma}\right)=\sigma_{N \mathbb{J}} \\
\Pi^{f}\left(n^{\gamma}\right)-c^{f, \gamma}-\Pi^{f}\left(n_{0} \mid K^{\gamma}\right)=\sigma_{F} \mathbb{J}
\end{array}\right.
$$

with $\mathbb{J}$ the joint surplus that is generated in the game. This allows us to get the expressions of the equilibrium contributions $c^{\gamma}$ and $c^{f, \gamma}$,

$$
\begin{aligned}
c^{\gamma}= & \frac{\sigma_{G}+\gamma \sigma_{F}}{\sigma_{N}+\sigma_{G}+\gamma \sigma_{F}}\left[\Pi\left(n^{\gamma}\right)-\Pi\left(n_{0} \mid K^{\gamma}\right)\right]-\frac{\sigma_{N}}{\sigma_{N}+\sigma_{G}+\gamma \sigma_{F}}\left[a W\left(n^{\gamma}\right)-a W\left(n_{0} \mid K^{\gamma}\right)\right] \\
& \quad-\gamma \frac{\sigma_{N}}{\sigma_{N}+\sigma_{G}+\gamma \sigma_{F}}\left[\Pi^{f}\left(n^{\gamma}\right)-\Pi^{f}\left(n_{0} \mid K^{\gamma}\right)\right] \\
c^{f, \gamma}= & \frac{-\sigma_{F}}{\sigma_{N}+\sigma_{G}+\gamma \sigma_{F}}\left[\Pi\left(n^{\gamma}\right)-\Pi\left(n_{0} \mid K^{\gamma}\right)\right]-\frac{\sigma_{F}}{\sigma_{N}+\sigma_{G}+\gamma \sigma_{F}}\left[a W\left(n^{\gamma}\right)-a W\left(n_{0} \mid K^{\gamma}\right)\right] \\
& +\left[\frac{\sigma_{N}+\sigma_{G}}{\sigma_{N}+\sigma_{G}+\gamma \sigma_{F}}\right]\left[\Pi^{f}\left(n^{\gamma}\right)-\Pi^{f}\left(n_{0} \mid K^{\gamma}\right)\right]
\end{aligned}
$$

We can now find the expression of the $\Omega$ function.

$$
\begin{aligned}
\Omega=a W\left(n_{0} \mid K_{0}\right)-a W\left(n^{\gamma} \mid K^{\gamma}\right)-c-\gamma c^{f} \\
=a W\left(n_{0} \mid K_{0}\right)-a W\left(n^{\gamma} \mid K^{\gamma}\right)-\frac{\sigma_{G}}{\sigma_{N}+\sigma_{G}+\gamma \sigma_{F}}\left[\Pi\left(n^{\gamma}\right)-\Pi\left(n_{0} \mid K^{\gamma}\right)\right] \\
\quad+\frac{\sigma_{N}+\gamma \sigma_{F}}{\sigma_{N}+\sigma_{G}+\gamma \sigma_{F}}\left[a W\left(n^{\gamma}\right)-a W\left(n_{0} \mid K^{\gamma}\right)\right]-\left[\frac{\gamma \sigma_{G}}{\sigma_{N}+\sigma_{G}+\gamma \sigma_{F}}\right]\left[\Pi^{f}\left(n^{\gamma}\right)-\Pi^{f}\left(n_{0} \mid K^{\gamma}\right)\right]
\end{aligned}
$$

We previously proved that $a W\left(n^{\gamma}\right)=a W\left(n_{0} \mid K^{\gamma}\right)$ because of the assumption of perfect complementarity of the two types of inputs and the initial underinvestment in non-services inputs.

$$
\begin{gathered}
\Omega=a W\left(n_{0} \mid K_{0}\right)-a W\left(n^{\gamma} \mid K^{\gamma}\right)-\frac{\sigma_{G}}{\sigma_{N}+\sigma_{G}+\gamma \sigma_{F}}\left[\Pi\left(n^{\gamma}\right)-\Pi\left(n_{0} \mid K^{\gamma}\right)\right] \\
-\left[\frac{\gamma \sigma_{G}}{\sigma_{N}+\sigma_{G}+\gamma \sigma_{F}}\right]\left[\Pi^{f}\left(n^{\gamma}\right)-\Pi^{f}\left(n_{0} \mid K^{\gamma}\right)\right]
\end{gathered}
$$

We define the bargaining power threshold by $\overline{\sigma_{G}}$ such that $\Omega\left(\overline{\sigma_{G}}\right)=0$.

$$
\frac{\overline{\sigma_{G}}}{\sigma_{N}+\overline{\sigma_{G}}+\gamma \sigma_{F}}=\frac{a W\left(n_{0} \mid K_{0}\right)-a W\left(n^{\gamma} \mid K^{\gamma}\right)}{\left[\Pi\left(n^{\gamma}\right)-\Pi\left(n_{0} \mid K^{\gamma}\right)\right]+\gamma\left[\Pi^{f}\left(n^{\gamma}\right)-\Pi^{f}\left(n_{0} \mid K^{\gamma}\right)\right]}
$$




\section{B Appendix}

Additional graphs to the subsection 4.1 As a robustness test, we conduct the same numerical simulations for two additional sets of different parameters. We set $\{A=1, v=0.9, a=0.99\}$ in Figure B-1 and $\{A=20, v=0.7, a=1.5\}$ in Figure B-2.

Figure B-1: Policy and commitment value for $A=1, v=0.9, a=0.99$.
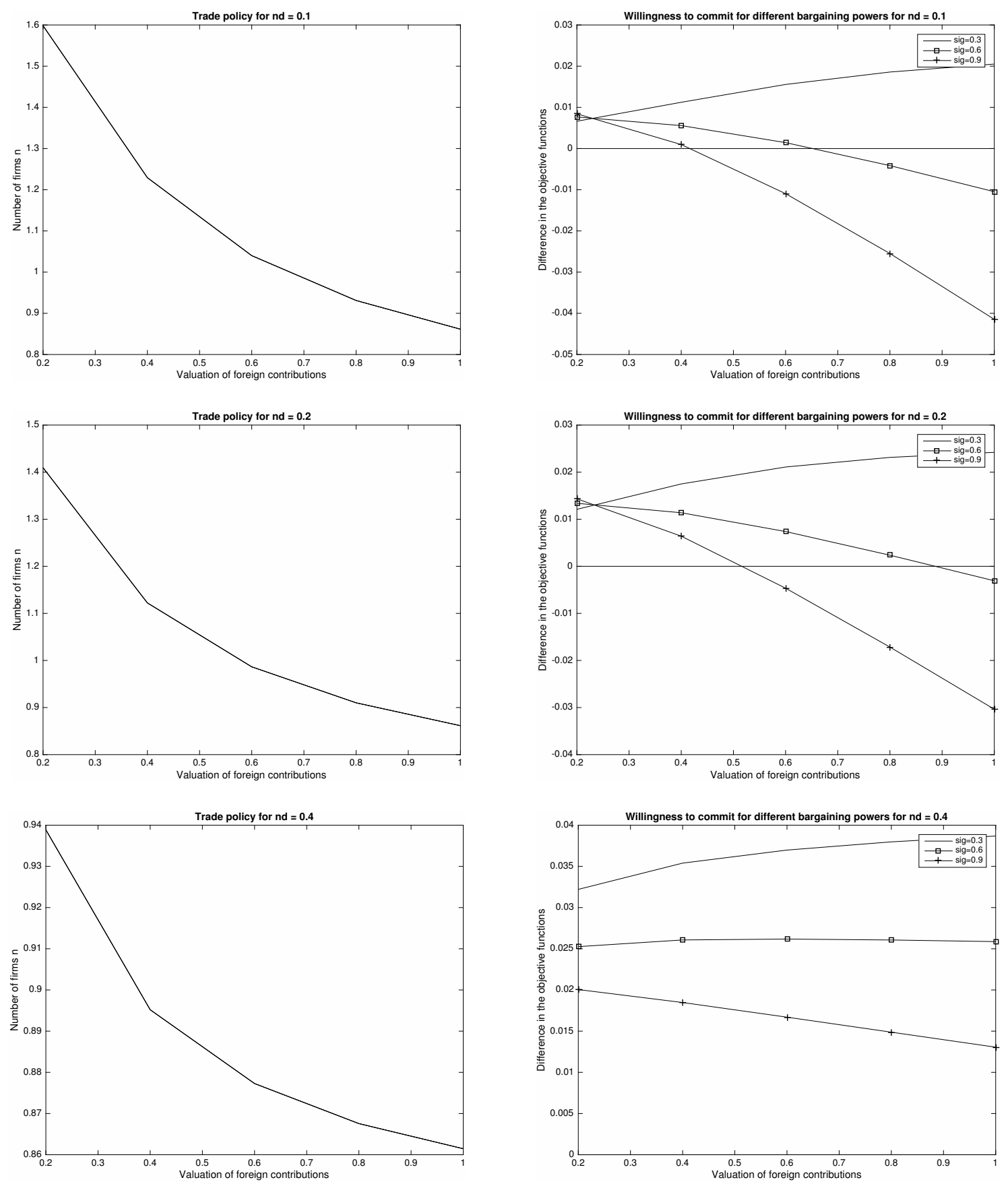
Figure B-2: Policy and commitment value for $A=20, v=0.7, a=1.5$.
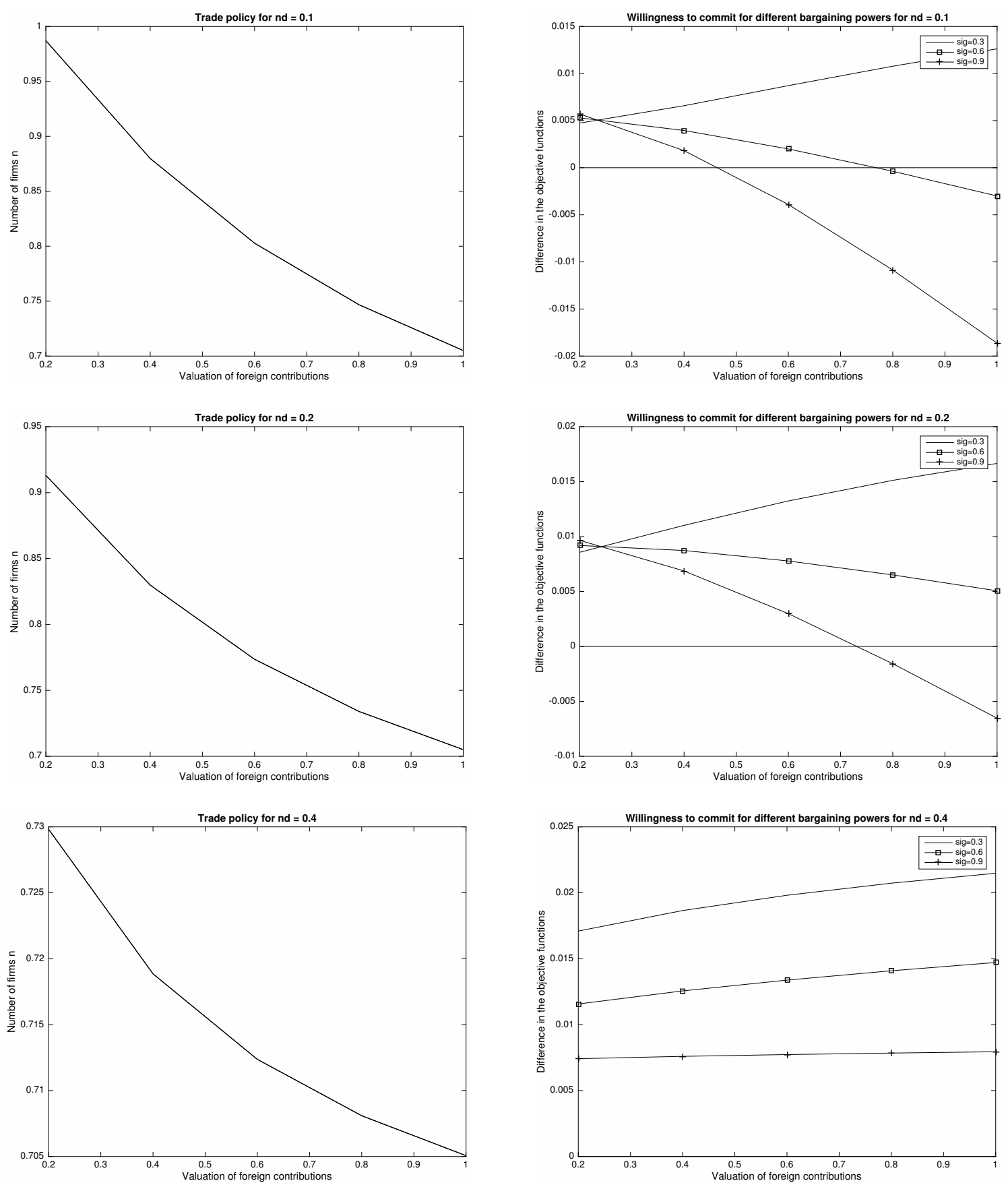